\title{
A new fuzzy mathematical model for green supply chain network design
}

\author{
Mohsen Sadegh Amalnick and Mohammad Mahdi Saffar*
}

School of Industrial Engineering, College of Engineering, University of Tehran, Tehran, Iran

\begin{tabular}{l}
\hline C H R O N I C L E \\
\hline Article history: \\
Received April 42016 \\
Received in Revised Format \\
June 162016 \\
Accepted July 122016 \\
Available online \\
July 152016 \\
\hline Keywords: \\
Closed loop supply chain network \\
design \\
Environmental optimization \\
Multi objective fuzzy \\
programming \\
Operational risks \\
CO2 Emission
\end{tabular}

\section{Introduction}

The supply chain is a network of suppliers, production centers, distribution centers, customer zones and channels between different layers organized to procure raw materials and convert them to the finished product and transport final products to customer zones in an efficient way (Pishvaee et al., 2011). In today's market, a strategically designed supply chain provides companies with competitive advantages. The most important strategic decision in supply chain management (SCM) is Supply chain network design that plays a significant role in both economic and environmental performance of the supply chain. Supply chain network design problem consist of determining the locations, capacities and number of network facilities and the material flow between layers of supply chain (Melo et al., 2009).

The concern about environmental issues caused by industries activities, results in governmental legislations to decrease the destructive environmental impact caused by factories and organizations. In other words, governments and consumers put pressures on companies to reduce the environmental impact of their activities and processes (Ilgin \& Gupta, 2010; Meade et al., 2007). Hence,

* Corresponding author. Tel.: +989122939830

E-mail: m.saffar@alumni.ut.ac.ir (M. M. Saffar)

(C) 2017 Growing Science Ltd. All rights reserved. doi: $10.5267 /$ j. ijiec.2016.7.003 
in recent years researchers and practitioners focus more on environmental supply chain management. The environmental supply chain management or green supply chain management integrates environmental aspects into SCM including both forward (from product design) and reverse (to end-oflife management of used products) supply chain networks. The ultimate aim is to consider environmental issues in decision making across the supply chain, especially the strategic decisions (Srivastava, 2007; Linton et al., 2007).

As it is mentioned earlier, the design and development of the logistic network is a strategic decision, it means its effects will remain for several years. Consequently, parameters such as demand of customers, transportation cost, production costs and environmental costs may change (Meepetchdee \& Shah, 2007). Therefore, those critical parameters are quite uncertain. Apart from that, since establishing and closing a facility is a time needed and costly activity, changing the facility location is impossible within a short time. Therefore, the supply chain network design problem should be modeled considering realistic assumptions to overcome the problems caused by deterministic mathematical models. Although, the uncertainty issues is more significant in reverse logistic networks because in reverse supply chain networks the quantity of returned products have to be faced with larger degree of uncertainty, the relevant literature indicates that most of the works assume that the parameters of the supply chain network are deterministic.

\section{Literature review}

Based on literature review, the common models of reverse supply chain network design are represented as mixed-integer programming (MIP) models. The variety of these models are from simple uncapacitated models to complex capacitated multi-stage models. The objective functions of these models are mostly aimed at reducing the cost of network design. Melo et al. (2009), and Klibi et al. (2010) conduct a survey on supply chain network design problems to demonstrate future research directions. Three separate research streams are introduced as follow.

\subsection{Reverse supply chain network design}

Reverse supply chain network design problem consists of the location of collection, recovery, recycling centers and capacities of these centers and material flows between the layers of supply chain (Dekker \& Fleischmann, 2004). As initial works in reverse supply chain network design problem, Krikke et al. (1999) proposed mathematical models. They propose a MILP model for a two-stage reverse logistics network. A number of metaheuristic algorithms were used to overcome the complexity of these models (e.g. Lee et al., 2009) and also heuristic (e.g. Aras \& Aksen, 2008) algorithms are proposed. Fleischmann et al. (1997) introduced a comprehensive survey on the application of mathematical modeling in reverse supply chain management. Barros et al. (1998) presented a MILP model for a sand recycling network solved by a heuristic algorithm. Jayaraman et al. (1999) presented a MILP model for reverse supply chain network design based on customer demands for recovered products. The goal of the presented model was to minimize the traditional costs. In this area several years later researchers have developed more complex models such as multi-product (e.g. Mutha \& Pokharel, 2009) and multi-objective (e.g. Fonseca et al., 2010). Jayaraman et al. (2003) developed their previous work to model the single product twolevel hierarchical location problem considering the reverse logistics operations of hazardous products. They also extend a heuristic to solve large-sized problem. Pati et al. (2008) introduced a mixed-integer goal programming model for paper recycling supply chain network design. The aims of objective functions are: (1) minimizing the positive deviation from the specified budget (2) minimizing the negative deviation from the minimum planned waste collection and (3) minimizing the positive deviation from the maximum limit of wastepaper. Uncertainty in the quantity of returned products is the important factors that should be included in the design of reverse logistics networks. According to this issue, Listes and Dekker (2005) developed the prior work done by Barros et al. (1998) a stochastic mixed-integer programming model for a sand recycling supply chain network design. 


\subsection{Closed-loop supply chain network design}

The design of forward and reverse logistics networks has a strong impact on the performance of each other. Thus, to avoid the sub-optimalities caused by the separated design, the design of the forward and reverse supply chain networks should be integrated (Pishvaee et al., 2010a; Fleischmann et al, 2001). Salema et al. (2007) tried to develop the Fleischmann et al. (2001) model and using stochastic mixed-integer programming approach under uncertainty. Lu and Bostel (2007) proposed a mixed-integer programming model including the both forward and reverse networks and their interactions simultaneously. To solve the presented model a lagrangian-based heuristic was extended. Pishvaee et al. (2010a) proposed a bi-objective mixed-integer linear programming model minimizing the total costs in a closed-loop logistics and maximizing the network responsiveness. A memetic algorithm was extended to solve the presented bi-objective MILP model. Thus, by integrated design of forward and reverse supply chain networks we also take the profits results and support the whole life cycle of good and product. General models (e.g. Wang \& Hsu, 2010a) and case-based (e.g. Ko \& Evans, 2007) are proposed by researchers. The imprecise nature of returned products causes a high degree of uncertainty in closed-loop and reverse supply chain network design problems. To cope with this uncertainty issues most of the relevant papers applied stochastic programming approaches (e.g. Pishvaee et al., 2009; El-Sayed et al., 2010). Because of the lack of historical data in real cases that is rarely available and the high computational complexity the use of stochastic programming models seems to be impossible in real cases. So, in recent years a few number of papers used more flexible approaches such as fuzzy programming (e.g. Wang \& Hsu, 2010b).

\subsection{Supply chain network design considering environmental issues}

Ilgin and Gupta (2010) presented a comprehensive review on company's conscious about environment and product recycle and recovery; we have surveyed some affiliate papers that work on environmental supply chain network design. Since the end-of-life (EOL) goods and products have important impact on environment this has make a need to extend and develop models for reverse supply chain (logistics) network design. Additionally, as it seen in relevant literature a thin part of works incorporates the environmental issues into supply chain network design decisions. Hugo and Pistikopoulos (2005) presented a bi-objective mathematical programming model to consist environmental impact in forward supply chain network problem. The proposed model maximizing the total profit and moreover, minimizes the environmental impact by applying LCA principles. For electronic equipment recycling network a model was presented by Quariguasi Frota Neto et al. (2009) to minimize traditional cost objective in addition to cumulative energy demand and wastes. Frota Neto et al. (2008) proposed a biobjective linear programming model for forward supply chain network design considering environmental impacts in European pulp and paper industry. However, the developed model is able to optimize the quantity of flow between supply chain layers and ignores the other decisions such as determining the location, number of facilities and capacity of them. All of the mentioned papers in the area of environmental supply chain network design avoid the integrated design of forward and reverse networks and incorporating the environmental issues into decision making model. Also, all of the above mentioned papers are incapable to model the uncertainty of parameters in supply chain network design problem. Since supply chain network design and relevant MIP models belong to the class of NP-hard problems, great number of heuristic algorithms (e.g. Listeş \& Dekker, 2005) and meta heuristics such as simulated annealing (e.g. Pishvaee et al., 2010b), genetic algorithm (e.g. Min et al., 2006), scatter search (e.g. Du \& Evans, 2008) tabu search (e.g. Lee \& Dong, 2008) are applied and developed to solve these models. To fill the literature gap, in this paper we developed a practical bi-objective fuzzy mathematical programming model for supply chain network design problem considering environmental factors that is able (1) to optimize both traditional cost and environmental objectives in the design of the logistic network, (2) integrate the design of forward and reverse supply chain networks to neglect the suboptimalities caused by separated design of forward and reverse logistics (3) handle the uncertainty of parameters caused by incompleteness or unavailability and imprecise nature of parameters. 


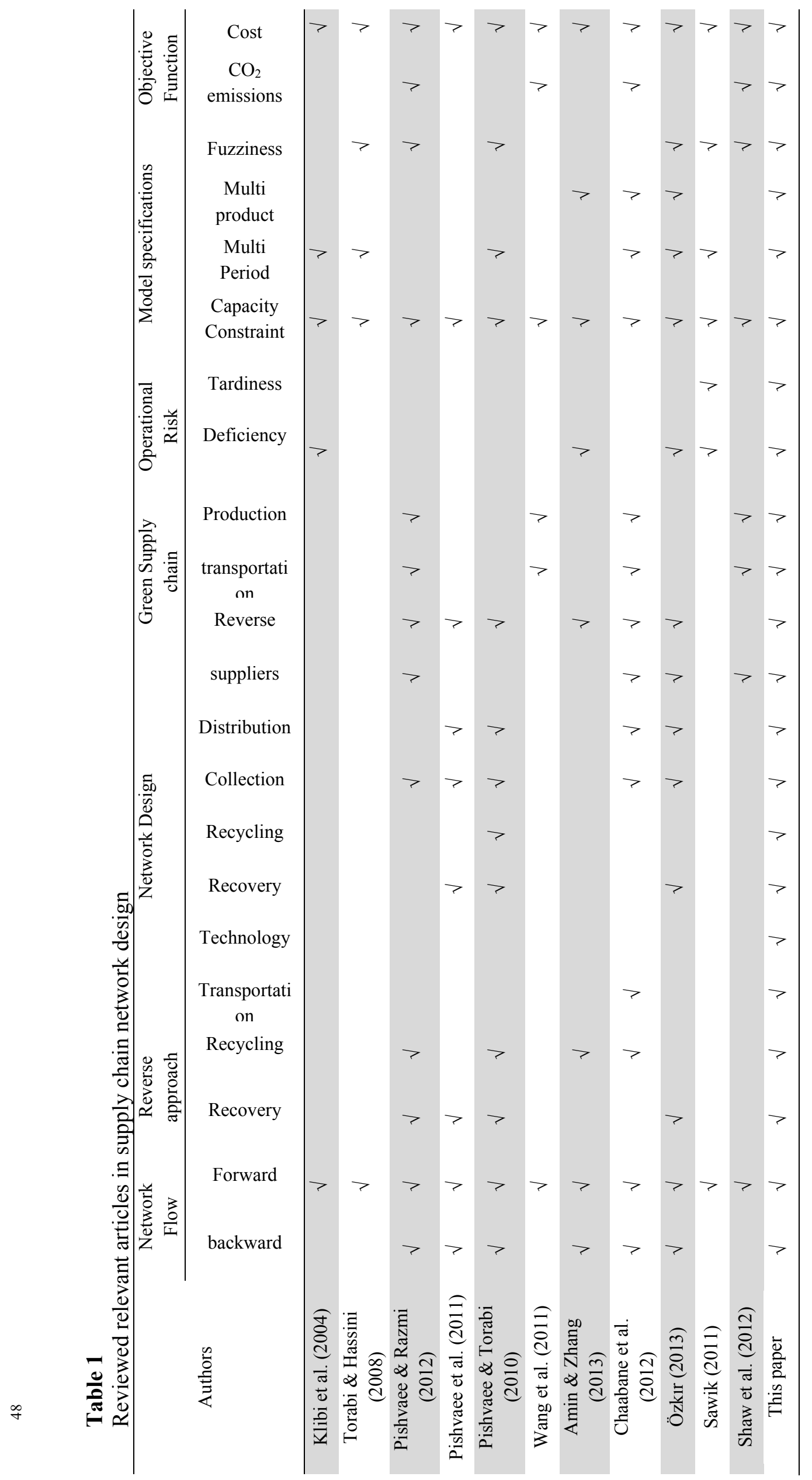


Also, this work uses an efficient solution approach that is making a reasonable tradeoff between traditional cost and environmental objectives. Thus, among the existing works in the relevant literature the earlier mentioned properties, differentiate this work from other works. In a short notice, the gap among most relevant papers have been represented in Table 1 and this paper indicate the gaps it fills.

El-Sayed et al. (2010) developed a stochastic mixed integer programming model to integrating both forward and reverse supply chain network design under demand and returned products uncertainty. The objective function is to maximize the total profit. However, there are two major drawbacks in using stochastic approach: (1) for uncertain parameters there is not enough historical data in many real cases, therefore, for these parameters we can rarely obtain the exact and actual random distributions. Moreover, the chance constraints increase significantly the computational complexity and (2) in most of relevant previous papers that work on reverse supply chain network design, the uncertainty of parameters in this problem are modeled through scenario based stochastic programming. So a large number of scenarios used in reporting the uncertain parameters lead to computationally complex problems. Fuzzy set theory as an appropriate alternative provides an appropriate frame work to handle various kind of uncertainty (Negoita et al., 1978). To the best of our knowledge that gain from surveying the relevant literature, this research is a primary work applying the possibilistic optimization approach in green closed-loop supply chain network design area. However, a few papers apply fuzzy optimization approach for forward and reverse supply chain network design (e.g. Selim \& Ozkarahan, 2008; Pishvaee \& Torabi, 2010). Wang and Shu (2007) proposed a possibilistic model for the supply chain network design of a new product and moreover they applied a genetic algorithm to find near optimal solutions. There are other research works using fuzzy approach in the context of logistic planning at tactical and operational levels (e.g. Torabi \& Hassini, 2008). The objective of this research work is to develop a multi-objective possibilistic optimization model for a closed-loop supply chain network design that integrates the design of both forward and reverse supply chain networks under uncertain demands, returned products, capacities, cost and delivery times. The objectives of concerned model include total cost minimization and minimizing the total tardiness of delivered products. The main contributions of this research work that differentiate this work from the related existing ones in the literature; can be summarized as follows:

-Proposing an efficient and realistic new supply chain network design model that designs both forward and reverse supply chains simultaneously moreover integrates the strategic decisions with tactical decisions in the context of closed loop supply chain that consider environmental impacts in production centers, recovery centers, recycle centers and shipment. Thus, by this proposed integrated model we can also avoid the sub-optimalities caused by separated design of the forward supply chain and reverse supply chains and the separated design between strategic decision making process and tactical levels. To the best of our knowledge that gained from surveying in the relevant literature there is no work considering both of these integrations and including environmental factor in a single model for multi products and multi period network. (i.e. Pishvaee et al., 2010a; Lee \& Dong, 2008) only integrated the forward and reverse supply chains but ignoring the integration of the strategic decision and tactical level, And Pishvaee and Torabi (2010) however considered both of these integration but ignoring the environmental factors and the proposed model formulate supply chain for single product however it seems more realistic that such a vast supply chain can produce different kind of products with different demands and different process time and production cost. On the other hand, some research works (see Shen, 2007) integrates decision making processes in strategic level and tactical levels but ignores integrating forward and reverse supply chains design.

- Proposing a possibilistic programming optimization model which handles different sources of uncertainty influencing closed-loop supply chains by jointly containing incompleteness and imprecise nature of parameters.

- Despite the case-based models(e.g. Pishvaee \& Razmi, 2012) or research papers that only model the recovery or recycling process (e.g. Fleischmann et al., 2001; Lee \& Dong, 2008; Üster et al., 2007), this paper presents a general and realistic network that it can handling both recovery and recycling processes 
with different technology in reverse network and also can consider different type of production technology in forward network, and therefore can be used to the different kind of industries (with single product or multi product) such as vehicle (e.g. Üster et al., 2007) and electronic industries (e.g. Lee \& Dong, 2008). Moreover, our proposed model also contains a second group of customers that called recycled material customer. Notably, many previous works only consider the product customers and ignore the second group of customers.

- To the best of our knowledge it is the first work that designs a general and realistic closed loop supply chain network considering environmental impact in production activities, shipment activities, recovering and recycling process simultaneously and additionally integrates strategic decision process and tactical levels.

Briefly, this work proposes a general and practical and also realistic multi-objective possibilistic model for integrating forward/reverse supply chain network design environmentally that is able to: (1) integrate the design of forward and reverse network in supply chains, as well as integrate strategic decision level such as facility location and with tactical decision like material flow ones at each period, (2) as a general network can handle recovery and recycling processes with different technology in reverse network for multi products supply chain,(3) as a facility of reverse supply chain consider the customers of recycled material,(4) allow to appropriate trade-off between two important objectives function ,the conventional total costs and total $\mathrm{CO}_{2}$ emission (as an important environment factors) through the different processes(production, recovery, recycling and shipment) in forward and reverse supply chain and finally (5) handle different system uncertainties and environment uncertainties influencing the design of closedloop supply chain by considering incompleteness or unavailability of parameters and imprecise nature of parameters that used in the possibilistic programming approach. The organization of this paper is then as follows. The concerned problem is defined in Section 3. And the multi-objective fuzzy mathematical programming model presented in this section. The interactive solution method is presented in Section 4. The computational results introduced in section 5. Finally, the some directions for future studies and concluding remarks are presented in Section 6.

\section{Problem definition}

The closed loop supply chain network presented in this paper is a multi echelon, multi product and multi period supply chain network type that includes, suppliers, production centers, distribution centers, customer zones, collection centers, recovery and recycle centers and material customers. A new product, produced by production center, is transferred to the given customer zones via distribution centers to satisfy the demand of each customer zone and also the demand of customers must be satisfied in each period. Noted that the fuzzy percentage of manufactured products in production center are wreck, and since it assumed that the damage products cannot recognize in network, first they delivered to the customers and then the customers turn them back to the customer zones and therefore the brands of company decreases and we define it as failure cost. If the capacity of production center is not enough for manufacturing the needed products, they can purchase from suppliers and the purchased products shipped to the production center for final packing. The fuzzy percentage of purchased products are wreck and likewise the fuzzy percentage of them are shipped to the production center with delay, and as it assumed in the model that all of demand must be satisfied, so the customers wait for receiving the products and a penalty give to the customer, we define this penalty as shortage cost. Noted that consequently the shortage cost is a fuzzy parameter. The location of suppliers, production center, customer zones and material customers, are fixed and predefined. We also consider multiple capacity levels for distribution centers in each candidate location. Notably, since different capacity for facilities in supply chain network has strong influence on the supply chain network costs and its environmental impact, it is vital to consider this issue in modeling (see Amiri, 2006). The structure of considered closed loop supply chain network is illustrated in Fig. 1. In the reverse flows, the used products, which are deficient and are required to be fixed or recycled, collected from customer zones and in collection centers they categorized in the 
recoverable or unrecoverable groups by quality testing and disassembly activities. The recoverable products are shipped to recovery centers and scraped products are shipped to recycling facilities. The recovered products then return to the distribution centers so as to be distributed among customer zones. On the other hand, scrapped products, after processing in the recycle center and converting to the raw material, are shipped in to the material customers to be sold as raw materials and gain income for the network. The concerned network in this paper has a general structure which is able to handle both recovery activities and recycling activities (as it can be seen Fig.1) and therefore can be used by different kind of industries and firms such as vehicle industries (e.g. Melo et al., 2009) and electronic industries (e.g. Du \& Evans, 2008). Because of incompleteness or unavailability of data in real world problems, especially in strategic decision process, most of the data embedded in such forward and reverse supply chain network design problem have an imprecise nature. Thus, for model the lack of knowledge about these ill-known data and parameters are presented by fuzzy numbers described by their possibility distribution (see Pishvaee et al., 2009; Hanson \& Hitchcock, 2009). By including multiple periods in the proposed model we could consider a decision horizon and thus the flow quantities between different layers of closed-loop supply chain belonging to different echelons of supply chain are determined according to demand of customer zones, return and other parameters at each period. Apart from that, this model considers multi commodity to endow different organization and industries producing multi products with the efficacy and applicability. Moreover, as mentioned before, this model enable industries to strike a fair balance between economic optimization and environmental issues. This obtained by considering $\mathrm{CO}_{2}$ emission factors as an objective function to be optimized .By applying this approach we can integrate the strategic level location decision process and the tactical material flow decisions with considering reverse flows and environmental factors (see Frota Neto et al., 2008). Under abovementioned assumption the decisions to be addressed in, include determining locations and the number of required distribution centers, collection centers, recovery and recycle centers and the number of machines with suitable technology to be purchased in production, recovery and recycle centers, as well as aggregated material flow between closed loop supply chain network nodes and their corresponding transportation modes. As mentioned earlier, our model incorporates the decisions about transportation modes and production technologies in the strategic logistics network design problem. Our motivation for such incorporation goes back to significant impact of transportation modes and production technologies on total environmental impact as well as total cost of logistics network. Also, the integration of such tactical decisions with the strategic network design ones ensure to escape from the sub optimality resulting from separated decision making for the tactical and strategic level decisions (see Pishvaee et al., 2010a; Shen, 2007). Furthermore, when creating such a green logistics network, it is important to provide an economic and environmental trade-off for the decision maker. For this reason, it is more desirable to formulate both of environmental and economic aspects as design objectives rather than constraints. Therefore, the ultimate goal could be expressed as determining the problem's decisions while making a reasonable tradeoff between these two conflicting objectives and satisfying the system constraints.

The other assumptions used in the developed network design formulation are as follow:

- Demands of each kind of products must be satisfied and all of the returned products from customer zones must be collected.

- In the forward flow of network each kind of products are shipped through a pull mechanism.

- In the reverse side of network returned products are shipped through a push mechanism.

- The shipment system has different mode of transportation with different cost and $\mathrm{CO}_{2}$ emission.

- Locations of supplier, production center (plant), customer zones and material customers are fixed and predefined.

- A predefined percent of previous period demand of each customer zone is assumed as returned products from related customer zones in the current period.

- A predefined percent of returned products is assumed as recoverable product. 
- Without loss of generality, multi products with different specification (like production cost, demand, recovery cost, rate of return, fractional rate, volume and etc.) are moved through the network.

The structure of considered closed loop supply chain network is illustrated in Fig. 1.

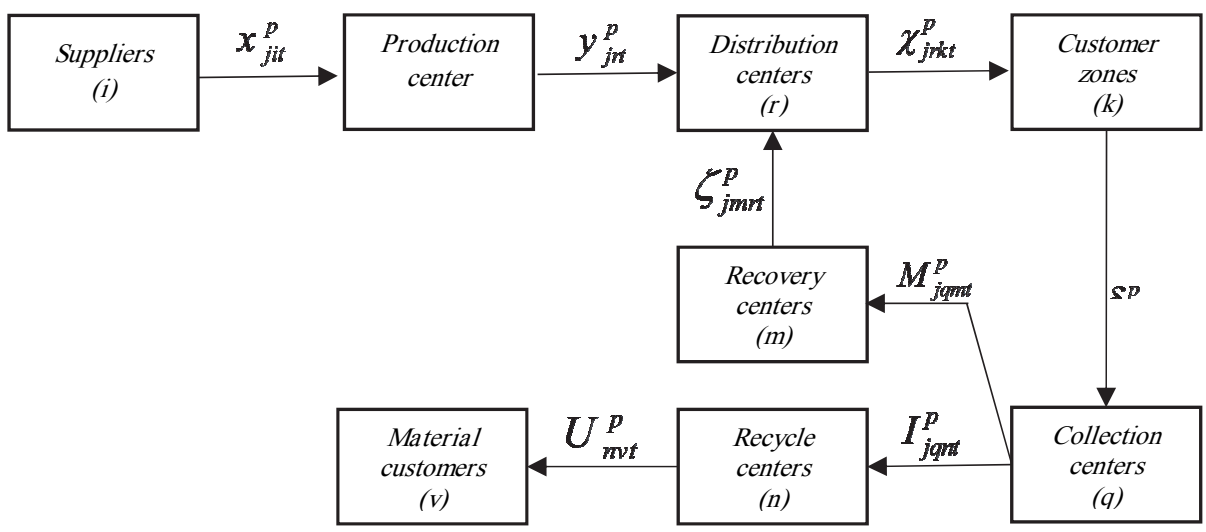

Fig. 1. The integrated supply chain network

The following notations are used in the formulation of the proposed model:

\subsection{Indices and Sets}

$i \quad$ Index of suppliers $i=0,1, \ldots, I$

$j \quad$ Index of different parts $j=0,1, \ldots, J$

$r \quad$ Index of candidate locations for the distribution centers $r=0,1, \ldots, R$

$v \quad$ Index of fixed locations for the material costumer zones $v=1,2, \ldots, V$

$k \quad$ Index of fixed locations for the costumer zones $k=1,2, \ldots, K$

$q \quad$ Index of candidate locations for the collection centers $q=1,2, \ldots, Q$

$m \quad$ Index of candidate locations for the recovery centers $m=1,2, \ldots, M$

$n \quad$ Index of candidate locations for the recycle centers $n=1,2, \ldots, N$

$z \quad$ Index of capacity levels available for distribution centers $z=1,2, \ldots, Z$

$l \quad$ Index of different technologies available for production centers $l=1,2, \ldots, L$

$o$ Index of different technologies available for recovery centers $o=1,2, \ldots, O$

$s \quad$ Index of different technologies available for recycle centers $s=1,2, \ldots, S$

$p \quad$ Index of available transportation modes $p=1,2, \ldots, P$

$t \quad$ Index of time periods $t=1,2, \ldots, T$

\subsection{Parameters}

\section{- Cost}

\section{.1. Fixed Cost}

$\tilde{H}_{r}^{z} \quad$ Fixed cost of opening distribution center $r$ with capacity level $z$

$\tilde{h}_{q} \quad$ Fixed cost of opening collection center $q$

$\tilde{r}_{m} \quad$ Fixed cost of opening recovery center $m$

$\tilde{f_{n}} \quad$ Fixed cost of opening recycles center $n$ 
.2. Purchasing Technology

$C s^{l} \quad$ Purchasing cost per machine with $l$ technology in the plant

$C s_{m}^{o} \quad$ Purchasing cost per machine with $o$ technology at recovery center $m$

$C s_{n}^{s} \quad$ Purchasing cost per machine with $s$ technology at recycle center $n$

3. Operating

$\tilde{h}_{j}^{l} \quad$ Producing cost per unit $j$ produced in the plant with technology $l$

$\tilde{\rho}_{j m}^{o} \quad$ Remanufacturing cost per unit $j$ at recovery center $m$ with technology $o$

$\tilde{\tau}_{j n}^{s} \quad$ Recycling cost per unit $j$ at recycle center $n$ with technology $s$

4. Shipping

$\tilde{T}_{j i}^{p} \quad$ Transportation cost for shipping one product unit $j$ from supplier $i$ with transportation mode $p$

$\tilde{c}_{j r}^{p} \quad$ Transportation cost for shipping one product unit $j$ from plant to distribution center $r$ with transportation mode $p$

$\tilde{a}_{j r k}^{p} \quad$ Transportation cost for shipping one product unit $j$ from distribution center $r$ to costumer zone $k$ with transportation mode $p$

$\tilde{b}_{j k q}^{p} \quad$ Transportation cost for shipping one product unit $j$ of returned products from customer zone $k$ to collection center $q$ with transportation mode $p$

$\tilde{v}_{j q m}^{p} \quad$ Transportation cost for shipping one product unit $j$ of recoverable products from collection center $q$ to recovery center $m$ with transportation mode $p$

$\tilde{s}_{j m r}^{p} \quad$ Transportation cost for shipping one product unit $j$ of recovered products from recovery center $m$ to distribution center $r$ with transportation mode $p$

$\tilde{w}_{j q n}^{p} \quad$ Transportation cost for shipping one product unit $j$ of collected products from collection center $q$ to recycle center $n$ with transportation mode $p$

$\tilde{V_{n v}^{p}} \quad$ Transportation cost for shipping one recycled unit from recycle center $n$ to material costumer zone $v$ with transportation mode $p$

\section{- Capacity}

.1. Time

$\mathrm{Ti}^{l} \quad$ Available time for one machine with $l$ technology in the plant

$P \tilde{t}_{j}^{l} \quad$ Time needed for producing one product unit $j$ with $l$ technology in the plant

$T M^{o} \quad$ Available time for one machine with $o$ technology in the recovery center

$P \tilde{T M}{ }_{j}^{o} \quad$ Time needed for recovering one product unit $j$ with $o$ technology in recovery center

$T N^{s} \quad$ Available time for one machine with $s$ technology in the recycle center

$P \tilde{T N}{ }_{j}^{s} \quad$ Time needed for recycling one product unit $j$ with $s$ technology in recycle center

\section{.2. Volume and Operating}

$C_{j i} \quad$ Capacity of supplier $i$ for producing part $j$

$V o R_{r}^{z} \quad$ Available volume for keeping parts of distribution center $r$ with capacity level $z$ 
- $\mathrm{CO}_{2}$ Emission

1. Shipping

$\tilde{t}_{j i}^{p} \quad \mathrm{CO}_{2}$ equivalent emission per product unit $j$ shipped from supplier $i$ by transportation mode $p$

$\tilde{\phi}_{j r}^{p} \quad \mathrm{CO}_{2}$ equivalent emission per product unit $j$ shipped from production center to distribution center $r$ by transportation mode $p$

$\tilde{J}_{j r k}^{p} \quad \mathrm{CO}_{2}$ equivalent emission per product unit $j$ shipped from distribution center $r$ to costumer zone $k$ by transportation mode $p$

$\tilde{\vartheta}_{j k q}^{p} \quad \mathrm{CO}_{2}$ equivalent emission per product unit $j$ shipped from costumer zone $k$ to collection center $q$ by transportation mode $p$

$\tilde{\gamma}_{j q m}^{p} \quad \mathrm{CO}_{2}$ equivalent emission per product unit $j$ shipped from collection center $q$ to recovery center $m$ by transportation mode $p$

$\tilde{\psi}_{j q n}^{p} \quad \mathrm{CO}_{2}$ equivalent emission per product unit $j$ shipped from collection center $q$ to recycle center $n$ by transportation mode $p$

$\tilde{\pi}_{j m r}^{p} \quad \mathrm{CO}_{2}$ equivalent emission per product unit $j$ shipped from recovery center $m$ to distribution center $r$ by transportation mode $p$

$\tilde{\partial}_{n v}^{p} \quad \mathrm{CO}_{2}$ equivalent emission per recycled unit shipped from recycle center $n$ to material costumer zone $v$ by transportation mode $p$

.2. Operating

$\tilde{L}_{j}^{l} \quad \mathrm{CO}_{2}$ equivalent emission per product unit $j$ produced by the plant with technology $l$

$\tilde{\varepsilon}_{j}^{o} \quad \mathrm{CO}_{2}$ equivalent emission per product unit $j$ recovered with technology $o$

$\tilde{\kappa}_{j}^{s} \quad \mathrm{CO}_{2}$ equivalent emission per product unit $j$ recycled with technology $s$

- Rates

$\tilde{q}_{j i} \quad$ Expected defect rate of supplier $i$ in quality of part $j$

$D \tilde{e}_{j i} \quad$ Expected delay rate of product type $j$ purchased from supplier $i$

$\tilde{\vartheta}_{j} \quad$ Expected defect rate of the plant for quality of part $j$

$\tilde{\omega}_{j k t} \quad$ Rate of return percentage product type $j$ from customer zone $k$ at the time period $t$

$\tilde{r}_{j k t} \quad$ The quantity of returned product type $j$ from customer zone $k$ at the time period $t$

$\tilde{\wp}_{j} \quad$ Rate of recoverable percentage product type $j$

$\mathrm{Fr}_{j} \quad$ Quantity of material per unit product type $j$

- Others

$p_{j i} \quad$ Cost per product unit $j$ purchased from supplier $i$

$\tilde{e}_{j} \quad$ Per unit failure cost for the part $j$

$\tilde{\sigma}_{j} \quad$ Per unit shortage cost for the part $j$

$\tilde{C} o_{v} \quad$ Price per unit of recycled product proposed by material customer $v$ 
$\tilde{d}_{j k t} \quad$ Demand of costumer zone $k$ for product $j$ at time period $t$

$V_{j} \quad$ Volume of one unit of product $j$

\section{- Decision Variables}

\section{.1. Shipping}

$x_{j i t}^{p} \quad$ Quantity of product part $j$ purchased from supplier $i$ and transfer to production center by transportation mode $p$ at time period $t$

$y_{j r t}^{p} \quad$ Quantity of product unit $j$ shipped from production center to distribution center $r$ by transportation mode $p$ at time period $t$

$\chi_{j r k t}^{p} \quad$ Quantity of product unit $j$ shipped from distribution center $r$ to customer zone $k$ by transportation mode $p$ at time period $t$

$\delta_{j k q t}^{p} \quad$ Quantity of returned product unit $j$ shipped from customer zone $k$ to collection center $q$ by transportation mode $p$ at time period $t$

$M_{j q m t}^{p} \quad$ Quantity of collected product unit $j$ shipped from collection center $q$ to recovery center $m$ by transportation mode $p$ at time period $t$

$I_{j q n t}^{p} \quad$ Quantity of collected product unit $j$ shipped from collection center $q$ to recycle center $n$ by transportation mode $p$ at time period $t$

$\zeta_{j m r t}^{p} \quad$ Quantity of recovered product unit $j$ shipped from recovery center $m$ to distribution center $r$ by transportation mode $p$ at time period $t$

$U_{n v t}^{p} \quad$ Quantity of recovered product shipped from recycle centers $n$ to material costumer zone $v$ by transportation mode $p$ at time period $t$

\section{.2. Operating and Purchasing}

$z_{j t}^{l} \quad$ Quantity of products $j$ manufactured in the plant with technology $l$ at time period $t$

$N M^{l} \quad$ Number of purchased machines with $l$ technology in the plant

$\mathrm{m}_{j m t}^{o} \quad$ Quantity of collected products $j$ in recovery center $m$ that recovered with $o$ technology at time period $t$

$N o M_{m}^{o} \quad$ Number of purchased machines with $o$ technology in recovery center $m$

$\mathrm{i}_{j n t}^{s} \quad$ Quantity of collected products $j$ in recycle center $n$ that recycled with $s$ technology at time period $t$

$\operatorname{NoN}_{n}^{s} \quad$ Number of purchased machines with $s$ technology in recycle center $n$

\section{.3. Binary Variables}

$\beta_{r}^{z}=1 \quad$ if a distribution center with capacity level $z$ is opened at location $r$; 0 , otherwise

$z_{q}=1 \quad$ if a collection center is opened at location $q$; 0 , otherwise

$\varpi_{m}=1 \quad$ if a recovery center is opened at location $m ; 0$, otherwise

$\wp_{n}=1 \quad$ if a recycle center is opened at location $n$; 0 , otherwise 
It should be noted that parameters with a tilde on indicate parameters tainted with uncertainty. These coefficients are estimated by suitable possibility distributions. In terms of the above notation, the concerned problem can be formulated as follows.

\subsection{Model Formulation}

\section{- Objective Functions}

As mentioned in earlier, two conflicting objective functions are considered in the formulation of closed loop supply chain network design problem: (1) minimization of conventional total cost and (2) minimization of total environmental impact $\left(\mathrm{CO}_{2}\right.$ emission $)$.

\section{First Objective: Cost Objective}

The total cost of green closed loop supply chain network design contains the fixed opening costs of facilities likes distribution centers, recovery and recycle centers and collection centers, and variable processing like producing, recycling and repairing cost, and transportation costs of flows between network facilities, and also purchasing machines in plant, recovery centers and recycle centers and shortage or failure penalty that should give to the customers (i.e., Total cost $=$ Fixed opening $\operatorname{costs}+$ Transportation + Processing costs + Purchased machines cost + shortage and failure cost). Thus, the first objective function can be formulated as follows.

$$
\begin{aligned}
& \operatorname{Min} \mathrm{W}_{1}=\sum_{i} \sum_{j} \sum_{p} \sum_{t} x_{j i t}^{p} \tilde{p}_{j i}+\sum_{i} \sum_{j} \sum_{p} \sum_{t} \tilde{q}_{j i} x_{j i t}^{p} \tilde{e}_{j}+\sum_{i} \sum_{j} \sum_{p} \sum_{t} D \tilde{e}_{j i} x_{j i t}^{p} \tilde{\sigma}_{j}+\sum_{i} \sum_{j} \sum_{p} \sum_{t} x_{j i t}^{p} \tilde{T}_{j i}^{p} \\
& +\sum_{l} \sum_{j} \sum_{t} z_{j t}^{l} \tilde{h}_{j}^{l}+\sum_{l} N M^{l} \cdot C s^{l}+\sum_{l} \sum_{j} \sum_{t} z_{j t}^{l} \cdot \tilde{\vartheta}_{j} \tilde{e}_{j}+\sum_{r} \sum_{j} \sum_{p} \sum_{t} y_{j t t}^{p} \tilde{c}_{r j}^{p}+\sum_{r} \sum_{z} \tilde{H}_{r}^{z} \cdot \beta_{r}^{z} \\
& +\sum_{r} \sum_{k} \sum_{j} \sum_{p} \sum_{t} \chi_{j k k t}^{p} . \tilde{a}_{j k k}^{p}+\sum_{k} \sum_{q} \sum_{j} \sum_{p} \sum_{t} \delta_{j k q t}^{p} \tilde{b}_{j k q}^{p}+\sum_{q} \tilde{h}_{q} \cdot Z_{q}+\sum_{q} \sum_{m} \sum_{j} \sum_{p} \sum_{t} M_{j q m t}^{p} \tilde{v}_{j q m}^{p} \\
& +\sum_{q} \sum_{n} \sum_{j} \sum_{p} \sum_{t} I_{j q n t}^{p} \tilde{w}_{j q n}^{p}+\sum_{m} \tilde{r}_{m} \cdot \varpi_{m}+\sum_{m} \sum_{o} \sum_{j} \sum_{t} \mathrm{~m}_{j m t}^{o} . \tilde{\rho}_{j m}^{o}+\sum_{m} \sum_{o} C s_{m}^{o} . N o M_{m}^{o}+\sum_{m} \sum_{r} \sum_{j} \sum_{p} \sum_{t} \zeta_{j m i t}^{p} \tilde{s}_{j m r}^{p} \\
& +\sum_{n} \sum_{v} \sum_{p} \sum_{t} U_{n v t}^{p} \tilde{V}_{n v}^{p}+\sum_{n} \tilde{f}_{n} \cdot \wp_{n}+\sum_{n} \sum_{s} \sum_{j} \sum_{t} \dot{\mathrm{i}}_{j n t}^{s} \cdot \tilde{\tau}_{j n}^{s}+\sum_{n} \sum_{s} C s_{n}^{s} \cdot \mathrm{NoN}_{n}^{s}-\sum_{n} \sum_{v} \sum_{p} \sum_{t} U_{n v t}^{p} \cdot C \tilde{o}_{v} .
\end{aligned}
$$

It should be noted that the transportation costs between network facilities are calculated by multiplying the transportation cost of one unit of shipping products per unit of distance (i.e., one kilometer) by the corresponding distance between two facilities.

\section{Second Objective: Total Environmental Impact (CO2 emission)}

The total $\mathrm{CO}_{2}$ emission in the concerned closed loop supply chain, comes from processing activities (such as producing units, recovery and recycle activities) and shipping parts between different layers of supply chain. So, the second objective function can be formulated as follows. 


$$
\begin{aligned}
& \min \mathrm{W}_{2}=\sum_{i} \sum_{j} \sum_{p} \sum_{t} x_{j i t}^{p} \cdot \tilde{t}_{j i}^{p}+\sum_{l} \sum_{j} \sum_{t} z_{j t}^{l} \cdot \tilde{L}_{j}^{l}+\sum_{r} \sum_{j} \sum_{p} \sum_{t} y_{j r t}^{p} \cdot \tilde{\phi}_{j r}^{p}+\sum_{r} \sum_{k} \sum_{j} \sum_{p} \sum_{t} \chi_{j r k t}^{p} \cdot \tilde{J}_{j r k}^{p} \\
& +\sum_{k} \sum_{q} \sum_{j} \sum_{p} \sum_{t} \delta_{j k q t}^{p} \cdot \tilde{\vartheta}_{j k q}^{p}+\sum_{q} \sum_{m} \sum_{j} \sum_{p} \sum_{t} M_{j q m t}^{p} \cdot \tilde{\gamma}_{j q m}^{p}+\sum_{q} \sum_{n} \sum_{j} \sum_{p} \sum_{t} I_{j q n t}^{p} \cdot \tilde{\psi}_{j q n}^{p} \\
& +\sum_{m} \sum_{o} \sum_{j} \sum_{t} m_{j m t}^{o} \cdot \tilde{\varepsilon}_{j}^{o}+\sum_{n} \sum_{s} \sum_{j} \sum_{t} i_{j n t}^{s} \cdot \tilde{\boldsymbol{\kappa}}_{j}^{s}+\sum_{m} \sum_{r} \sum_{j} \sum_{p} \sum_{t} \zeta_{j m r t}^{p} \cdot \tilde{\pi}_{j m r}^{p}+\sum_{n} \sum_{v} \sum_{p} \sum_{t} U_{n v t}^{p} \cdot \tilde{\partial}_{n v}^{p}
\end{aligned}
$$

\section{- Constraints}

$$
\begin{aligned}
& \sum_{p} x_{j i t}^{p} \leq \tilde{C}_{j i}, \quad \forall i, j, t, \\
& \sum_{r} \sum_{p} \chi_{j k k t}^{p} \geq \tilde{d}_{j k t}, \quad \forall j, t, k,
\end{aligned}
$$

Capacity of supplier constraint

Demand satisfaction

$\sum_{j} Z_{j t}^{l} \cdot P \tilde{t}_{j}^{l} \leq N M^{l} T \tilde{i}^{l}, \quad \forall l, t$,

Processing time in production center constraint

$\sum_{i} \sum_{p} x_{j i t}^{p}+\sum_{l} z_{j t}^{l}=\sum_{r} \sum_{p} \mathrm{y}_{j r t}^{p}, \quad \forall j, t$,

Plant flow balance constraint

$\sum_{p} \mathrm{y}_{j r t}^{p}+\sum_{m} \sum_{p} \zeta_{j m r t}^{p}=\sum_{k} \sum_{p} \chi_{j r k t}^{p}, \quad \forall r, j, t$,

Distribution centers flow balance constraint

$\sum_{q} \sum_{p} \delta_{j k q t}^{p} \geq \tilde{r}_{j k t}\left(=\tilde{\omega}_{j k t} \tilde{d}_{j k(t-1)}\right), \quad \forall k, j, t$,

Customer zones flow balance constraint

$\sum_{k} \sum_{p} \delta_{j k q t}^{p}=\sum_{m} \sum_{p} M_{j q m t}^{p}+\sum_{n} \sum_{p} I_{j q n t}^{p}, \quad \forall q, j, t$

Collection centers flow balance constraint

$\tilde{\wp}_{j} \cdot \sum_{k} \sum_{p} \delta_{j k q t}^{p}=\sum_{m} \sum_{p} M_{j q m t}^{p}, \quad \forall q, j, t$

Recoverable percentage constraint

$\sum_{q} \sum_{p} M_{j q m t}^{p}=\sum_{r} \sum_{p} \zeta_{j m r t}^{p}, \quad \forall m, j, t$

Recovery center flow balance constraint

$\sum_{o} m_{j m t}^{o}=\sum_{q} \sum_{p} M_{j q m t}^{p}, \quad \forall j, m, t$,

Processing on each parts shipped in to recovery center constraint

$\operatorname{Fr}_{j} \cdot \sum_{q} \sum_{p} I_{j q n t}^{p}=\sum_{v} \sum_{p} U_{n v t}^{p}, \quad \forall n, j, t$

Recycle center flow

balance

$$
\sum_{s} i_{j n t}^{s}=\sum_{q} \sum_{p} I_{j q n t}^{p}, \quad \forall j, t, n
$$

Processing on each parts shipped in to recycle center constraint 


$$
\begin{aligned}
& \sum_{j}\left[\left(\sum_{k} \sum_{p} \chi_{j r k t}^{p}\right) V o_{j}\right] \leq \sum_{z} V_{o} R_{r}^{z} \cdot \beta_{r}^{z}, \quad \forall r, t, \\
& \sum_{j} m_{j m t}^{o} \cdot P \tilde{T M}_{j}^{o} \leq T \tilde{M}^{o} \cdot N o M_{m}^{o}, \quad \forall m, o, t, \\
& \sum_{j} i_{j n t}^{s} \cdot P \tilde{T N}_{j}^{s} \leq T \tilde{N}^{s} . N o N_{n}^{s}, \quad \forall n, s, t, \\
& \sum_{z} \beta_{r}^{z} \leq 1, \quad \forall r, \\
& \sum_{k} \sum_{j} \sum_{p} \sum_{t} \delta_{j k q t}^{p} \leq M . z_{q}, \quad \forall q \\
& \sum_{q} \sum_{j} \sum_{p} \sum_{t} M_{j q m t}^{p}+\sum_{o} N_{o} M_{m}^{o} \leq M . \varpi_{m}, \quad \forall m, \\
& \sum_{q} \sum_{j} \sum_{p} \sum_{t} I_{j q n t}^{p}+\sum_{j} \sum_{s} \sum_{t} \mathrm{i}_{j n t}^{s} \leq M . \wp_{n}, \quad \forall n,
\end{aligned}
$$

Distribution center capacity constraint

Processing time in recovery center constraint

Processing time in recycle center constraint

Opening distribution center with unique capacity constraint

Collection center

construction constraint

Recovery center

construction constraint

Recycle center

construction constraint

Decision variables constraints (non-negativity and binary restrictions)

$$
\begin{aligned}
& \beta_{r}^{z}, z_{q}, \varpi_{m}, \wp_{n} \in\{0,1\}, \quad \forall r, z, q, m, n, \\
& x_{j i t}^{p}, y_{j r t}^{p}, \chi_{j k k t}^{p}, \delta_{j k q t}^{p}, M_{j q m t}^{p}, I_{j q n t}^{p}, \zeta_{j m r t}^{p} \in Z^{+}, \quad \forall p, j, i, t, r, k, q, m, n, \\
& U_{n v t}^{p} \geq 0, \quad \forall p, n, v, t, \\
& z_{j t}^{l}, N M^{l}, \mathrm{~m}_{j m t}^{o}, N o M_{m}^{o}, \mathrm{i}_{j n t}^{s}, \mathrm{NoN}_{n}^{s} \in Z^{+}, \quad \forall l, j, t, o, m, s, n .
\end{aligned}
$$

Constraints (3) ensure that the capacity constraint of all suppliers are considered. Constraints (4) ensures that all customers' demands must be satisfied. Constraints (5) guarantees that the products in the factory are not more than production capacity according to the available time of all technologies. Constraints (6), (7), (8), (9), (10), (11) and (13) strike a balance between what arrives and what leaves in production center, distribution center, customer zone, collection center, recovery center, and recycle center. Constraint (10) also calculate the rate of deficiency in commodities in customer zones. Constraints (12) and (14) assure that one type of technology in each center recovers or recycles all commodities. Constraints (15), (16), (17) define the capacity constraints in distribution, recovery, and recycling centers. Constraints (18) ensures if distribution center open in any location, it can construct with only one capacity level. And finally constraints (19), (20), (21) ensure that no commodity is sent to a distribution, recovery, or recycling center unless they are exist and also no machines purchased for recovery and recycle centers unless they are exist.

\section{The solution method}

According to the uncertainty classification describe in (Pishvaee \& razmi, 2012) in the supply chain network design problem we are facing imprecise parameters, therefore, in the proposed supply chin network design model, possibilistic programming approach is applied to handle the uncertain parameters. In possibilistic programming approach each ill-known parameter in proposed model has its possibility distribution. The possibility distribution for each uncertain coefficient demonstrates the possibility degree of occurrence of possible values. It is necessary to explained that the possibility distribution is 
mostly specified based on experts' knowledge or available data. Thus, the proposed supply chain network design model is a multi-objective possibilistic mixed integer programming, so to solve the proposed model a two-phased approach is applied.

In the literature, to confronting with possibilistic programming models a number of methods have been presented (e.g. Jiménez et al., 2007; Lai \& Hwang, 1992). Among the proposed methods in the literature, based on details below the Jimenez et al. (2007) method is chosen to handle the proposed model. First the Jimenez et al. method can support various kinds of membership functions such as trapezoidal, triangular and also nonlinear membership function symmetric and asymmetric forms. Second to solve fuzzy linear problems this method is computationally efficient because it can retain linearity of proposed model and do not increase inequality constraints and also the number of objective functions.

On the other hand several approaches have been presented in the literature to solve the multi-objective programming models. Because of their ability in measuring and editing the satisfaction degree of each objective function, the mostly used approaches in this domain are fuzzy programming methods. Fuzzy programming approaches vary from preliminary approaches (see Lai \& Hwang, 1993; Sakawa et al., 1987; Zimmermann, 1978) to more advanced methods (see Torabi \& Hassini, 2008; Li et al., 2006). For solving proposed multi objective model we have applied $\varepsilon$-constraint method that it is one of the fuzzy solution method. The main advantage of this methods compared with other priori methods explained subsequently. Based on Hwang et al. (1979) description, the $\varepsilon$-constraint method is known as a generation method or posteriori that is able to prepare suitable picture of whole Pareto optimal set for managers and decision makers. Then based on Pareto optimal the decision maker can select the most appropriate solution. Thus, according to comprehensive information, all of the solutions are discovered and the managers can make a decision more confidently. We refer the interested readers to Ehrgott (2005) for more information on $\varepsilon$-constraint method. Briefly, in the first step, to convert the proposed model into an equivalent auxiliary crisp model the method of Jimenez et al. (2007) is applied. In the second step, we have applied $\varepsilon$-constraint method (Ehrgott, 2005) to find the appropriate solution.

The auxiliary crisp model of the considered problem based on Jimenez et al. (2007) method can be formulated as follows.

\subsection{Auxiliary Crisp Model}

$$
\begin{aligned}
& \min \mathrm{W}_{1}=\sum_{i} \sum_{j} \sum_{p} \sum_{t} x_{j i t}^{p} \cdot\left(\frac{p_{j i}^{p}+2 p_{j i}^{m}+p_{j i}^{o}}{4}\right)+\sum_{i} \sum_{j} \sum_{p} \sum_{t}\left(\frac{q_{j i}^{p}+2 q_{j i}^{m}+q_{j i}^{o}}{4}\right) \cdot x_{j i t}^{p} \cdot\left(\frac{e_{j}^{p}+2 e_{j}^{m}+e_{j}^{o}}{4}\right) \\
& +\sum_{i} \sum_{j} \sum_{p} \sum_{t}\left(\frac{D e_{j i}^{p}+2 D e_{j i}^{m}+D e_{j i}^{o}}{4}\right) \cdot x_{j i t}^{p} \cdot\left(\frac{\sigma_{j}^{p}+2 \sigma_{j}^{m}+\sigma_{j}^{o}}{4}\right)+\sum_{i} \sum_{j} \sum_{p} \sum_{t} x_{j i t}^{p} \cdot\left(\frac{T_{j i}^{p}+2 T_{j i}^{p}+T_{j i}^{p}}{4}\right) \\
& +\sum_{l} \sum_{j} \sum_{t} z_{j t}^{l} \cdot\left(\frac{h_{j}^{l}+2 h_{j}^{l}+h_{j}^{l}}{4}\right)+\sum_{l} N M^{l} \cdot C s^{l}+\sum_{l} \sum_{j} \sum_{t} z_{j t}^{l} \cdot\left(\frac{\vartheta_{j}^{p}+2 \vartheta_{j}^{m}+\vartheta_{j}^{o}}{4}\right) \cdot\left(\frac{e_{j}^{p}+2 e_{j}^{m}+e_{j}^{o}}{4}\right) \\
& +\sum_{r} \sum_{j} \sum_{p} \sum_{t} y_{j r t}^{p} \cdot\left(\begin{array}{c}
p \\
c_{r j}^{p}+2 c_{r j}^{p}+c_{r j}^{p} \\
4
\end{array}\right)+\sum_{r} \sum_{z}\left(\frac{H_{r}^{z}+2 H_{r}^{z}+H_{r}^{z}}{4}\right) \cdot \beta_{r}^{z}
\end{aligned}
$$




$$
\begin{aligned}
& +\sum_{r} \sum_{k} \sum_{j} \sum_{p} \sum_{t} \chi_{j r k t}^{p} \cdot\left(\frac{\begin{array}{c}
p \\
a_{j r k}^{p}+2 a_{j r k}^{p}+a_{j r k}^{p}
\end{array}}{4}\right)+\sum_{k} \sum_{q} \sum_{j} \sum_{p} \sum_{t} \delta_{j k q t}^{p} \cdot\left(\frac{\begin{array}{c}
p \\
b_{j k q}^{p}+2 b_{j k q}^{p}+b_{j k q}^{p}
\end{array}}{4}\right) \\
& +\sum_{q}\left(\frac{h_{q}^{p}+2 h_{q}^{m}+h_{q}^{o}}{4}\right) \cdot Z_{q}+\sum_{q} \sum_{m} \sum_{j} \sum_{p} \sum_{t} M_{j q m t}^{p} \cdot\left(\frac{\begin{array}{c}
p \\
v_{j q m}^{p}+2 v_{j q m}^{p}+v_{j q m}^{p}
\end{array}}{4}\right) \\
& +\sum_{q} \sum_{n} \sum_{j} \sum_{p} \sum_{t} I_{j q n t}^{p} \cdot\left(\frac{\begin{array}{c}
p \\
w_{j q n}^{p}+2 \\
w_{j q n}^{p}+w_{j q n}^{o}
\end{array}}{4}\right)+\sum_{m}\left(\frac{r_{m}^{p}+2 r_{m}^{m}+r_{m}^{o}}{4}\right) \cdot \varpi_{m}
\end{aligned}
$$

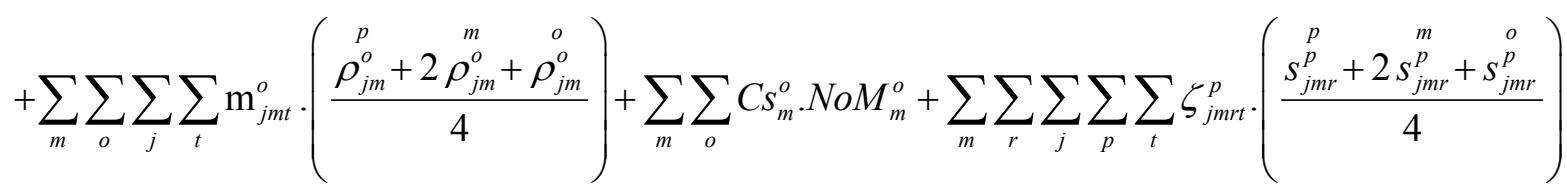

$$
\begin{aligned}
& +\sum_{n} \sum_{v} \sum_{p} \sum_{t} U_{n v t}^{p} \cdot\left(\frac{\begin{array}{c}
p \\
v_{n v}^{p}+2 v_{n v}^{p}+v_{n v}^{p}
\end{array}}{4}\right)+\sum_{n}\left(\frac{f_{n}^{p}+2 f_{n}^{m}+f_{n}^{o}}{4}\right) \cdot \wp_{n}+\sum_{n} \sum_{s} \sum_{j} \sum_{t} \mathrm{i}_{j n t}^{s} \cdot\left(\frac{\begin{array}{c}
p \\
\tau_{j n}^{s}+2 \tau_{j n}^{s}+\tau_{j n}^{s}
\end{array}}{4}\right) \\
& +\sum_{n} \sum_{s} C s_{n}^{s} \cdot \mathrm{NoN}_{n}^{s}-\sum_{n} \sum_{v} \sum_{p} \sum_{t} U_{n v t}^{p} \cdot\left(\frac{C o_{v}^{p}+2 C o_{v}^{m}+C o_{v}^{o}}{4}\right) \text {. } \\
& \min \mathrm{W}_{2}=\sum_{i} \sum_{j} \sum_{p} \sum_{t} x_{j i t}^{p} \cdot\left(\frac{\begin{array}{ccc}
p & m & o \\
t_{j i}^{p}+2 t_{j i}^{p}+t_{j i}^{p}
\end{array}}{4}\right)+\sum_{l} \sum_{j} \sum_{t} z_{j t}^{l} \cdot\left(\frac{\begin{array}{c}
p \\
L_{j}^{l}+2 L_{j}^{l}+L_{j}^{l}
\end{array}}{4}\right) \\
& +\sum_{r} \sum_{j} \sum_{p} \sum_{t} y_{j r t}^{p} \cdot\left(\begin{array}{c}
p \\
\phi_{j r}^{p}+2 \phi_{j r}^{p}+\phi_{j r}^{p} \\
4
\end{array}\right)+\sum_{r} \sum_{k} \sum_{j} \sum_{p} \sum_{t} \chi_{j r k t}^{p} \cdot\left(\begin{array}{c}
p \\
J_{j r k}^{p}+2 J_{j r k}^{p}+J_{j r k}^{p} \\
4
\end{array}\right) \\
& +\sum_{k} \sum_{q} \sum_{j} \sum_{p} \sum_{t} \delta_{j k q t}^{p} \cdot\left(\frac{\vartheta_{j k q}^{p}+2 \vartheta_{j k q}^{p}+\stackrel{o}{\vartheta_{j k q}^{p}}}{4}\right)+\sum_{q} \sum_{m} \sum_{j} \sum_{p} \sum_{t} M_{j q m t}^{p} \cdot\left(\frac{\begin{array}{c}
p \\
\gamma_{j q m}^{p}+2 \gamma_{j q m}^{p}+\gamma_{j q m}^{p}
\end{array}}{4}\right)
\end{aligned}
$$

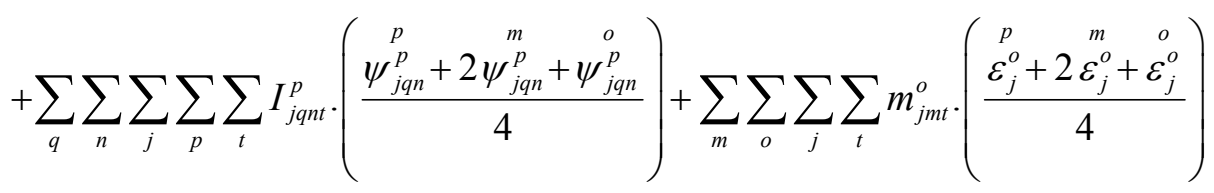

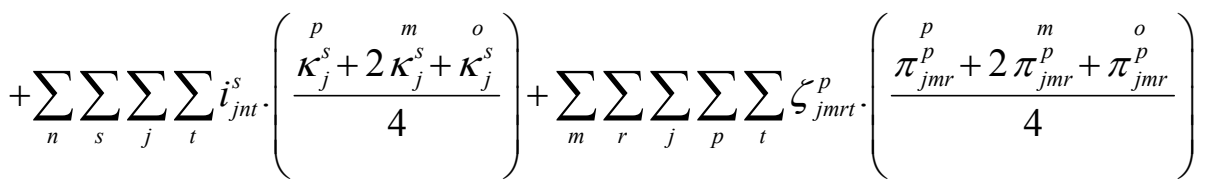

$$
\begin{aligned}
& +\sum_{n} \sum_{v} \sum_{p} \sum_{t} U_{n v t}^{p} \cdot\left(\frac{\partial_{n v}^{p}+2 \partial_{n v}^{p}+\partial_{n v}^{p}}{4}\right)
\end{aligned}
$$

subject to 
$\sum_{p} x_{j i t}^{p} \leq \alpha \cdot\left(\frac{C_{j i}^{p}+C_{j i}^{m}}{2}\right)+(1-\alpha) \cdot\left(\frac{C_{j i}^{m}+C_{j i}^{o}}{2}\right), \quad \forall i, j, t$,

$\sum_{r} \sum_{p} \chi_{j j k t}^{p} \geq \alpha \cdot\left(\frac{d_{j k t}^{m}+d_{j k t}^{o}}{2}\right)+(1-\alpha) \cdot\left(\frac{d_{j k t}^{p}+d_{j k t}^{m}}{2}\right), \quad \forall j, t, k$,

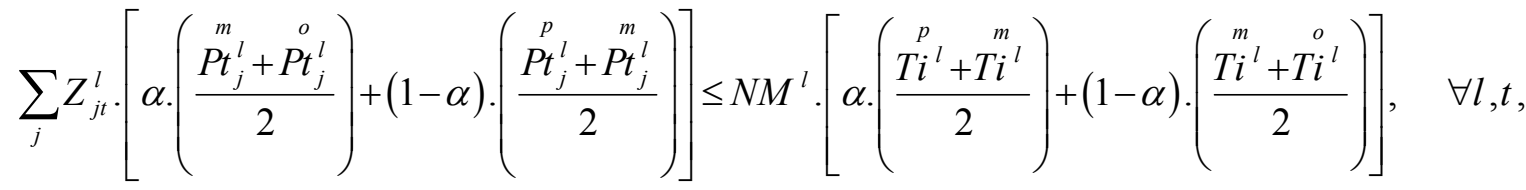

$\sum_{i} \sum_{p} x_{j i t}^{p}+\sum_{l} z_{j t}^{l}=\sum_{r} \sum_{p} \mathrm{y}_{j t t}^{p}, \quad \forall j, t$,

$\sum_{p} \mathrm{y}_{j r t}^{p}+\sum_{m} \sum_{p} \zeta_{j m i t}^{p}=\sum_{k} \sum_{p} \chi_{j k k t}^{p}, \quad \forall r, j, t$,

$\sum_{q} \sum_{p} \delta_{j k q t}^{p} \geq \alpha \cdot\left(\frac{r_{j k t}^{m}+r_{j k t}^{o}}{2}\right)+(1-\alpha) \cdot\left(\frac{r_{j k t}^{p}+r_{j k t}^{m}}{2}\right), \quad \forall k, j, t$,

$\sum_{k} \sum_{p} \delta_{j k q t}^{p}=\sum_{m} \sum_{p} M_{j q m t}^{p}+\sum_{n} \sum_{p} I_{j q n t}^{p}, \quad \forall q, j, t$

$\left[\frac{\alpha}{2} \cdot\left(\frac{\wp_{j}^{m}+\wp_{j}^{o}}{2}\right)+\left(1-\frac{\alpha}{2}\right) \cdot\left(\frac{\wp_{j}^{p}+\wp_{j}^{m}}{2}\right)\right] \cdot \sum_{k} \sum_{p} \delta_{j k q t}^{p} \leq \sum_{m} \sum_{p} M_{j q m t}^{p}, \quad \forall q, j, t$,

$\left[\left(1-\frac{\alpha}{2}\right) \cdot\left(\frac{\wp_{j}^{m}+\wp_{j}^{o}}{2}\right)+\frac{\alpha}{2} \cdot\left(\frac{\wp_{j}^{p}+\wp_{j}^{m}}{2}\right)\right] \cdot \sum_{k} \sum_{p} \delta_{j k q t}^{p} \geq \sum_{m} \sum_{p} M_{j q m t}^{p}, \quad \forall q, j, t$,

$\sum_{q} \sum_{p} M_{j q m t}^{p}=\sum_{r} \sum_{p} \zeta_{j m t t}^{p}, \quad \forall m, j, t$,

$\sum_{o} m_{j m t}^{o}=\sum_{q} \sum_{p} M_{j q m t}^{p}, \quad \forall j, m, t$,

$\mathrm{Fr}_{j} \cdot \sum_{q} \sum_{p} I_{j q n t}^{p}=\sum_{v} \sum_{p} U_{n v t}^{p}, \quad \forall n, j, t$,

$\sum_{s} i_{j n t}^{s}=\sum_{q} \sum_{p} I_{j q n t}^{p}, \quad \forall j, t, n$,

$\sum_{j}\left[\left(\sum_{k} \sum_{p} \chi_{j r k t}^{p}\right) V o_{j}\right] \leq \sum_{z} V o R_{r}^{z} \cdot \beta_{r}^{z}, \quad \forall r, t$,

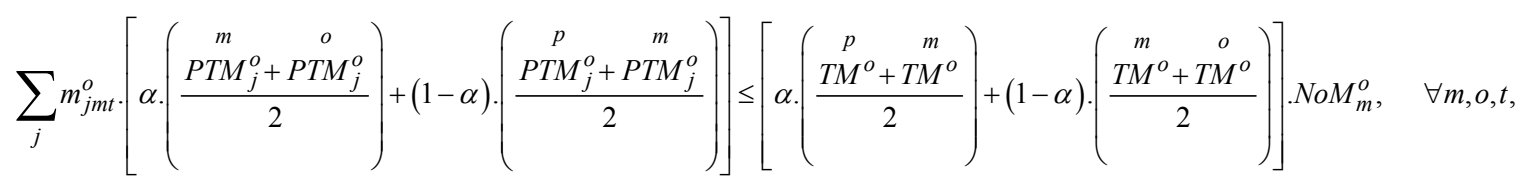

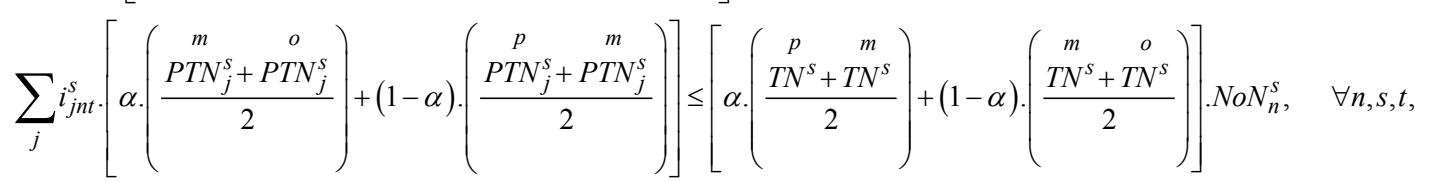

$\sum_{z} \beta_{r}^{z} \leq 1, \quad \forall r$ 


$$
\begin{aligned}
& \sum_{k} \sum_{j} \sum_{p} \sum_{t} \delta_{j k q t}^{p} \leq M . z_{q}, \quad \forall q, \\
& \sum_{q} \sum_{j} \sum_{p} \sum_{t} M_{j q m t}^{p}+\sum_{o} N o M_{m}^{o} \leq M . \varpi_{m}, \quad \forall m, \\
& \sum_{q} \sum_{j} \sum_{p} \sum_{t} I_{j q n t}^{p}+\sum_{j} \sum_{s} \sum_{t} \mathrm{i}_{j n t}^{s} \leq M . \wp_{n}, \quad \forall n, \\
& \beta_{r}^{z}, z_{q}, \varpi_{m}, \wp_{n} \in\{0,1\}, \quad \forall r, z, q, m, n, \\
& x_{j i t}^{p}, y_{j r t}^{p}, \chi_{j r k t}^{p}, \delta_{j k q t}^{p}, M_{j q m t}^{p}, I_{j q n t}^{p}, \zeta_{j m r t}^{p} \in Z^{+}, \quad \forall p, j, i, t, r, k, q, m, n, \\
& U_{n v t}^{p} \geq 0, \quad \forall p, n, v, t, \quad \\
& z_{j t}^{l}, N M^{l}, \mathrm{~m}_{j m t}^{o}, N o M_{m}^{o}, \mathrm{i}_{j n t}^{s}, \mathrm{NoN}_{n}^{s} \in Z^{+}, \quad \forall l, j, t, o, m, s, n .
\end{aligned}
$$

\section{Computational experiments}

To illustrate the validity of the presented model in this research work and the applicability and usefulness of the applied hybrid solution, several numerical experiment are examined and the results are represented in this section. Because of the lack of data in these models two test problems with different sizes are designed based on expert's knowledge and available data gathered by Pishvaee and Torabi (2010). The size of test problems are shown in Table 2.

\section{Table 2}

The size of test problems

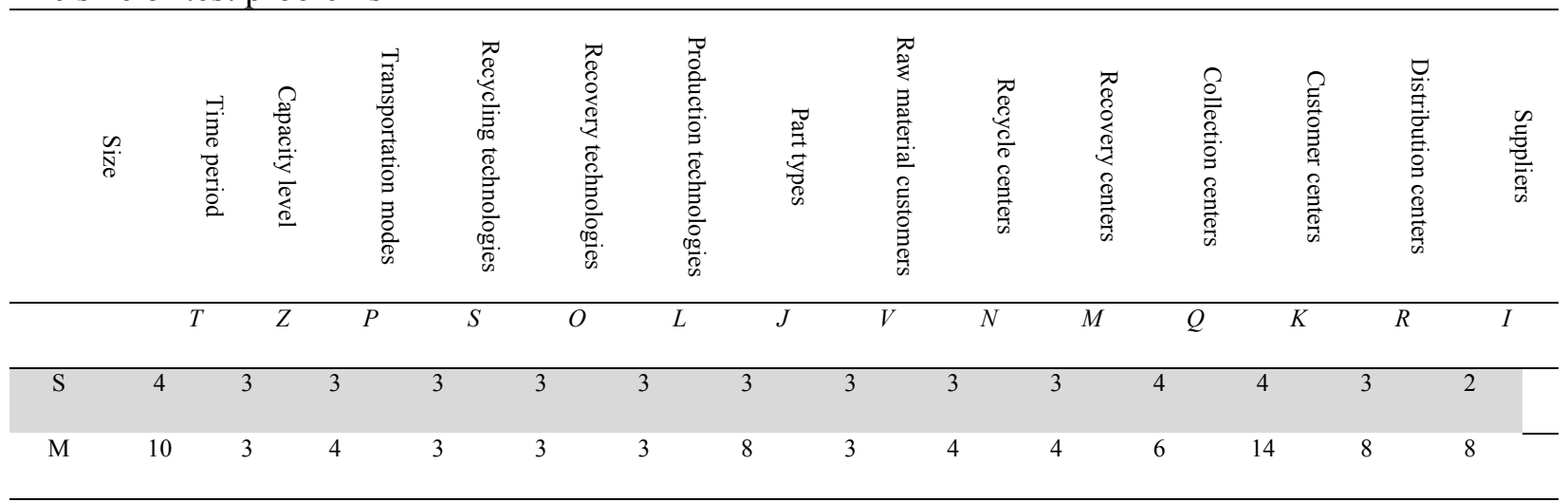

The sources of random generation of the most likely values shown in Table 3.

Notably, $c x i^{p}$ is transportation cost of one unit of shipping part per unit of distance with transportation mode $p$ and also $g x i^{p}$ is amount $(\mathrm{Kg})$ of $\mathrm{CO}_{2}$ emission of one unit of shipping part per unit of distance with transportation mode $p$.

Based on Lai and Hwang (1992) description, for producing triangular fuzzy parameters first the most likely $\left(c^{m}\right)$ value for each coefficient generated by using uniform distributions shown in Table 3 , and then two numbers $\left(r_{1}, r_{2}\right)$ are chosen between $(0.2,0.8)$ randomly, and optimistic points $\left(c^{o}\right)$ and pessimistic points $\left(c^{p}\right)$ are calculated as follows:

$$
\begin{aligned}
& c^{o}=\left(1+r_{1}\right) \cdot c^{m} \\
& c^{p}=\left(1-r_{2}\right) \cdot c^{m}
\end{aligned}
$$


Table 3

Sources of random generation of the most likely values

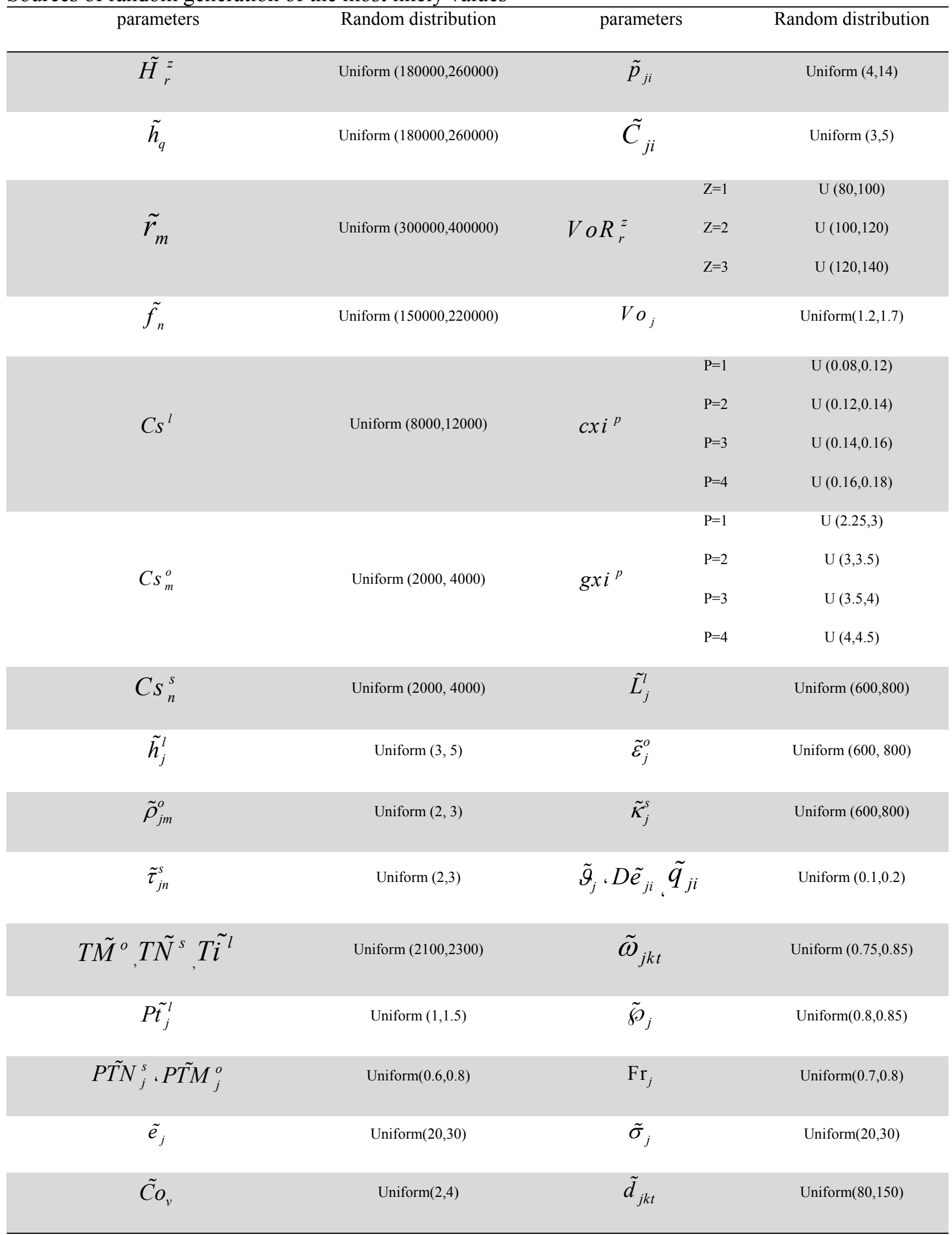


It should be noted that for calculating transportation cost between two facilities of supply chain network first, for each facility, we generate two random number using uniform distribution between $(0,100)$, and they indicate the length and width of corresponding facility in coordinate (Amiri, 2006). Second, we calculate the Euclidean distance between two facilities. Third, transportation costs between facilities, for each transportation mode are calculated by multiplying the corresponding $c x i^{p}$ (i.e., one kilometer) by the corresponding Euclidean distance between two facilities. For calculating the amount of $\mathrm{CO}_{2}$ that emitted by each transportation mode we can also multiply the $g x i^{p}$ by corresponding Euclidean distance between two facilities.

To solve and analyze the performance of the proposed possibilistic models, all of the mathematical models are coded in GAMS 24.2.2 optimization software and all tests are carried out on an Intel core i7 2.70GHZ computer with 4GB RAM and the results for "S" size problem are report in Table 4 and for "M" size problem are report in Table 5. To carry out the $\varepsilon$-constraint method, the $\mathrm{CO}_{2}$ emission objective is used as a side constraint and the cost objective is kept in the model as objective function.

In order to performance testing, different minimum acceptable feasibility degrees (i.e., $\alpha$ levels: $0.7,0.8$ and 0.9) are applied and the behavior of the objective functions based on different $\alpha$ level shown in Fig. 2 (for "S" size problem) and Fig. 3 (for "M" size problem). As it can be seen in Tables 4 and 5 six Paretooptimal solutions are generated for each $\alpha$ level by the aid of the $\varepsilon$-constraint method (Ehrgott, 2005).As they are indicated in Fig. 2 and Fig. 3 when the minimum acceptable feasibility degree $(\alpha$ level) is augmented the value of cost objective function and $\mathrm{CO}_{2}$ emission objective function increases. Thus, as the manager decided to face uncertainty issue with a higher confidence level, the value of both costs and $\mathrm{CO}_{2}$ emission are also augmented because to satisfy demand and other constraints in higher $\alpha$ level, needs more resources. According to the decision makers and managers preferences the value of $\alpha$ level can be varied.

By studying the number of constructed facilities in Tables 4 and 5 we can obtain that the first objective function for minimizing the total cost has a tendency towards logistics network centralization. Thus, at higher satisfaction degrees of cost objective function compared with lower ones, less number of distribution, collection, recovery and recycle centers is opened. On the other hand, the $\mathrm{CO}_{2}$ emission objective function to minimize the total $\mathrm{CO}_{2}$ emission (environmental impact) has a tendency towards decentralized supply chain network. The result could be simply explained when the second objective is more important compared with the first one for decision makers (in decentralized network), because more facilities of supply chain network are opened (compared with centralized configuration) so, to transport products between two facilities, more and probably shorter paths are available therefore less $\mathrm{CO}_{2}$ emitted from shipping activities. 

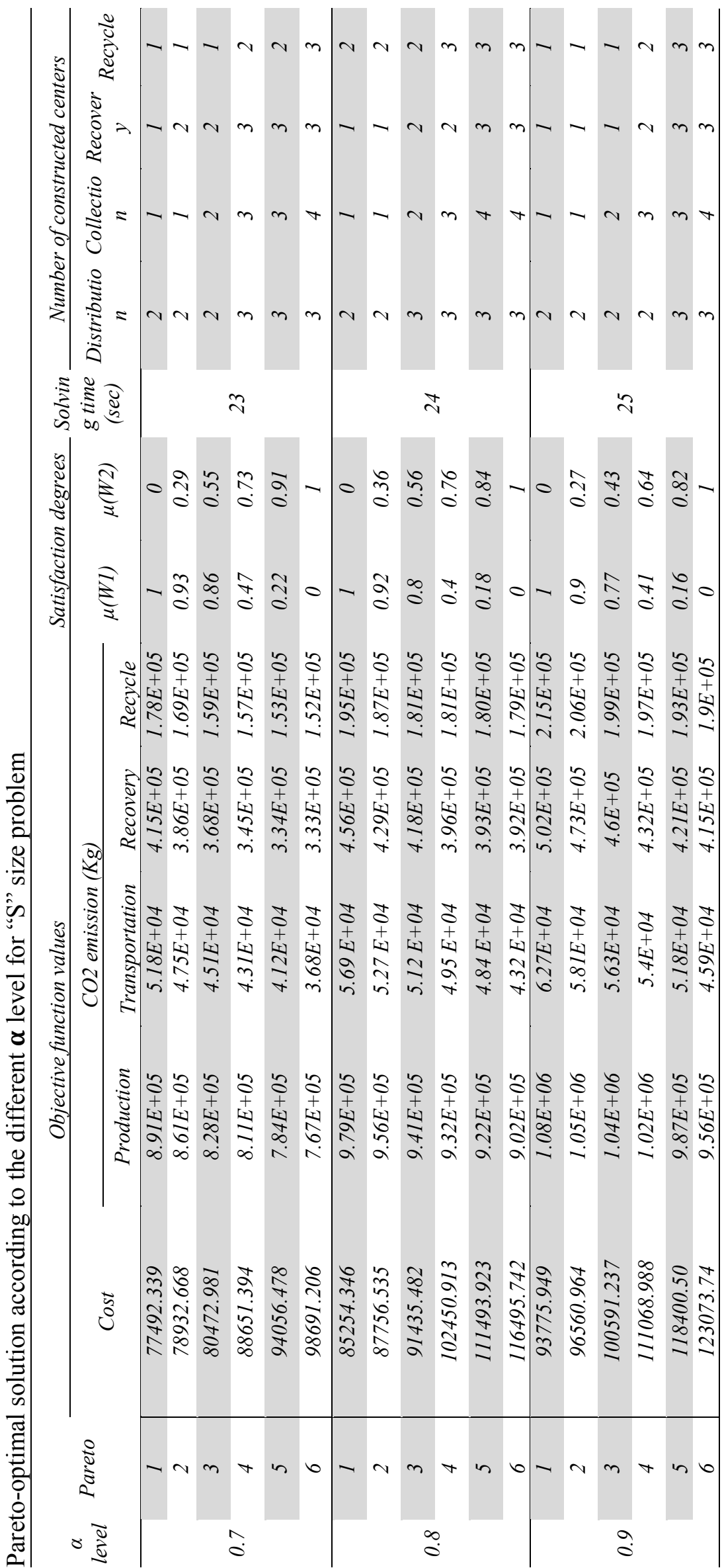


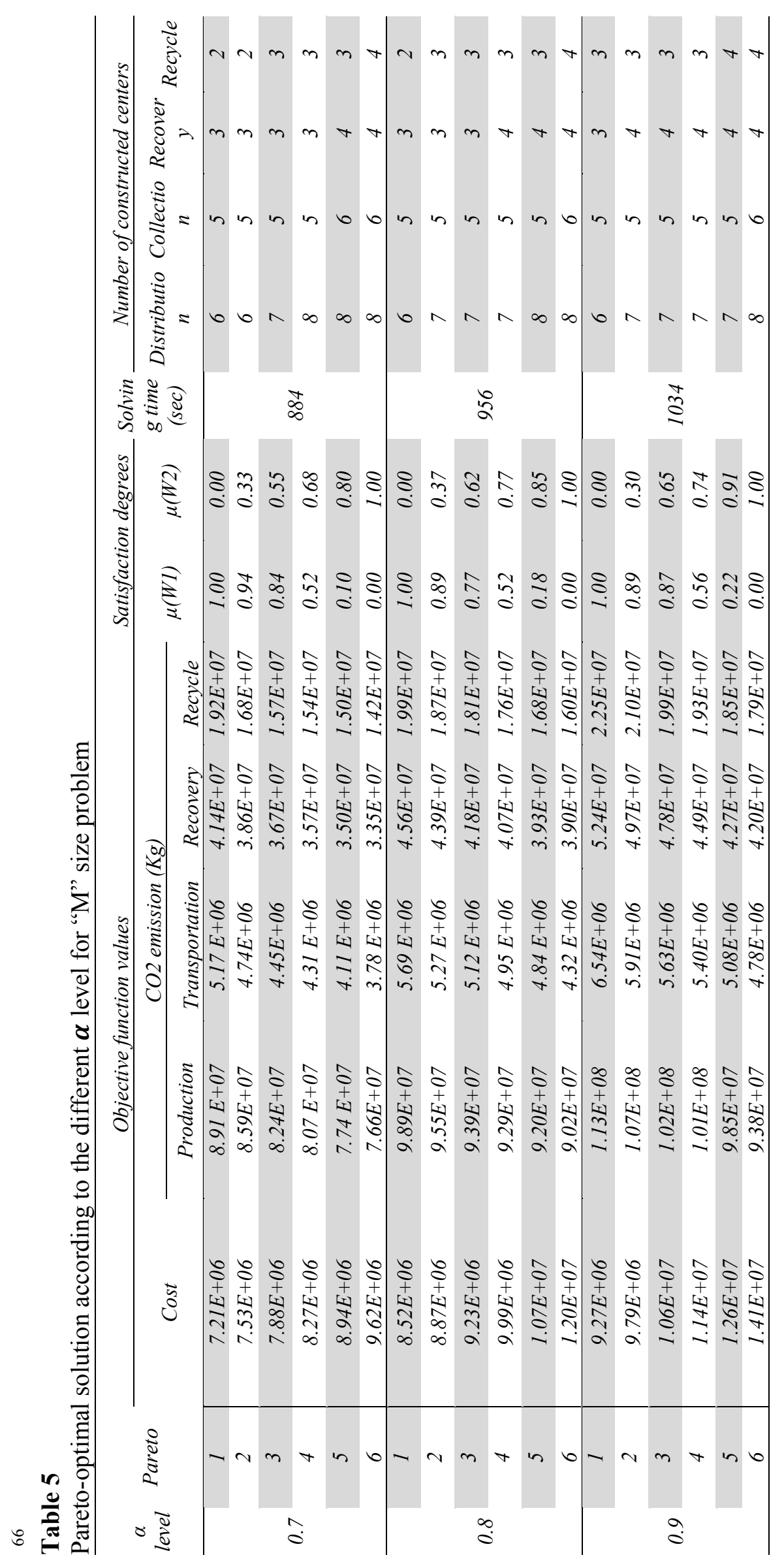


Also it can be seen in Fig. 2 and Fig. 3, the cost objective functions and $\mathrm{CO}_{2}$ emission objective function are in conflict with each other. It means that increasing in one of them leads to decreasing another one and vice versa. Totally, it can be concluded that the $\varepsilon$-constraint method is appropriate and qualified methods for solving the auxiliary crisp model of supply chain network design problems. Notably if the number of objective functions are more than two, the other MCDM methods such as analytic hierarchy process can be applied to set the objective weights.

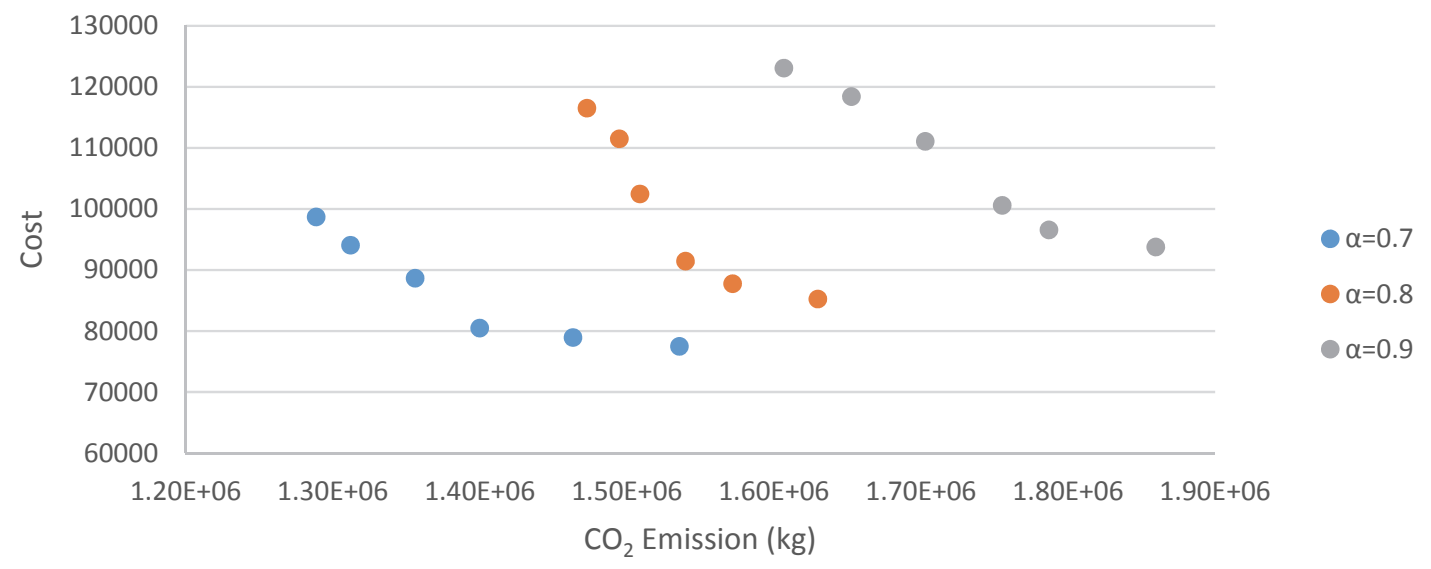

Fig. 2. Sensitivity Analysis of Different $\alpha$ Level for "S" Size Problem

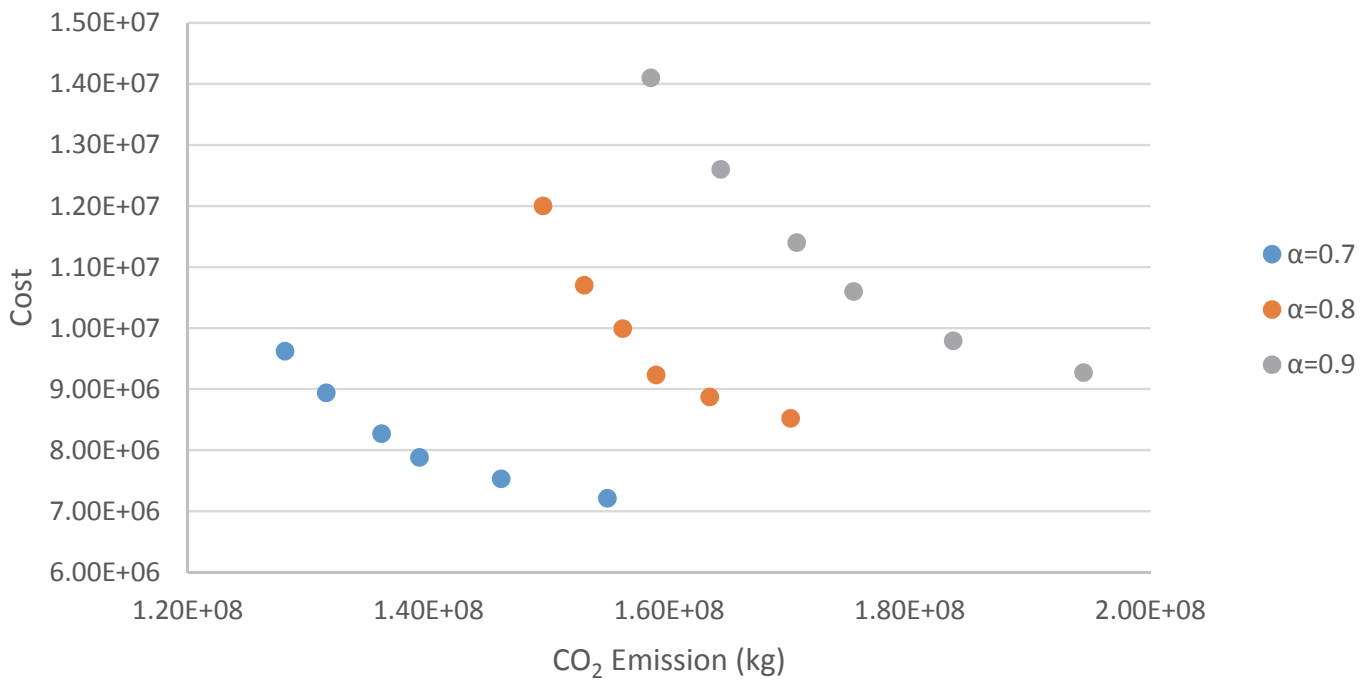

Fig. 3. Sensitivity Analysis of Different $\alpha$ Level for "M" Size Problem

As it can be seen in Fig. 4 based on available data the reason of more than half $\mathrm{CO}_{2}$ emission are production activities. It should be considered by decision makers that if less $\mathrm{CO}_{2}$ emission is more desirable, it is logical that invest on production center and purchased machines with less rate of $\mathrm{CO}_{2}$ emission. In other languages, based on available data it seems the most important factor in air pollution is production activities, so investigate on improving production technology is one of the issues that should be considered by experts and researchers. 


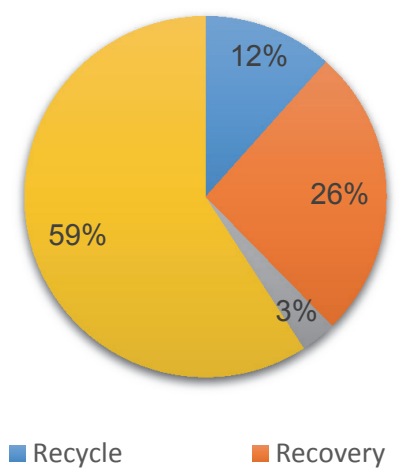

\section{Conclusion}

Fig. 4. CO2 Emission Percentage

In recent years, environmental issues have become an important topic and researchers investigated problems considering environmental impacts. The design of supply chain network considering environmental impacts is a very critical and complex decision that forms in an uncertain and dynamic environment. Despite the past relevant papers, this work integrates the design of both forward supply chains and reverse supply chains besides considering the environmental impacts in the supply chain. Since most of the parameters in closed loop supply chain network have imprecise nature, a possibilistic programming approach is used to model closed loop supply chain. To solve the proposed model, an interactive fuzzy solution approach is applied by combining Jimenez et al. (2007) method and $\varepsilon$ constraint (Ehrgott, 2005) method. The effectiveness of the developed fuzzy optimization model as well as the usefulness of the applied solution approach is investigated through randomly generated test problems.

As it seems in the literature, the supply chain network design considering environmental aspects is still scarce. Thus, many possible future work directions can be defined in this area. For example addressing other supply chain network design problems such as tactical and operational planning problems are attractive investigates avenues with significant practical relevance. Social aspect is not addressed in this work, however it is an important issue regarding the supply chain sustainability, hence another attractive future research direction is incorporating the social issue into supply chain planning optimization models. Since supply chain network design belong to the class of NP-hard problem especially in large sized, developing efficient exact, heuristic or metaheuristic solution methods can be appealing in this context.

\section{References}

Amin, S. H., \& Zhang, G. (2013). A multi-objective facility location model for closed-loop supply chain network under uncertain demand and return. Applied Mathematical Modelling, 37(6), 4165-4176.

Amiri, A. (2006). Designing a distribution network in a supply chain system: Formulation and efficient solution procedure. European Journal of Operational Research, 171(2), 567-576.

Aras, N., \& Aksen, D. (2008). Locating collection centers for distance-and incentive-dependent returns. International Journal of Production Economics, 111(2), 316-333.

Barros, A. I., Dekker, R., \& Scholten, V. (1998). A two-level network for recycling sand: a case study. European Journal of Operational Research, 110(2), 199-214.

Chaabane, A., Ramudhin, A., \& Paquet, M. (2012). Design of sustainable supply chains under the emission trading scheme. International Journal of Production Economics, 135(1), 37-49.

Dekker, R., \& Fleischmann, M. (Eds.). (2004). Reverse logistics: quantitative models for closed-loop supply chains. Springer.

Du, F., \& Evans, G. W. (2008). A bi-objective reverse logistics network analysis for post-sale service. Computers \& Operations Research, 35(8), 2617-2634.

Ehrgott, M. (2005). Multicriteria optimization (Vol. 2). Berlin: Springer.

El-Sayed, M., Afia, N., \& El-Kharbotly, A. (2010). A stochastic model for forward-reverse logistics network design under risk. Computers \& Industrial Engineering, 58(3), 423-431. 
Fleischmann, M., Beullens, P., Bloemhof-Ruwaard, J. M., \& Wassenhove, L. N. (2001). The impact of product recovery on logistics network design. Production and Operations Management, 10(2), 156-173.

Fleischmann, M., Bloemhof-Ruwaard, J. M., Dekker, R., Van der Laan, E., Van Nunen, J. A., \& Van Wassenhove, L. N. (1997). Quantitative models for reverse logistics: a review. European Journal of Operational Research, 103(1), $1-17$.

Fonseca, M. C., García-Sánchez, Á., Ortega-Mier, M., \& Saldanha-da-Gama, F. (2010). A stochastic bi-objective location model for strategic reverse logistics. Top, 18(1), 158-184.

Frota Neto, J. Q., Bloemhof-Ruwaard, J. M., Van Nunen, J. A. E. E., \& Van Heck, E. (2008). Designing and evaluating sustainable logistics networks. International Journal of Production Economics, 111(2), 195-208.

Hanson, J. J., \& Hitchcock, R. W. (2009, September). Towards sustainable design for single-use medical devices. In Engineering in Medicine and Biology Society, 2009. EMBC 2009. Annual International Conference of the IEEE (pp. 5602-5605). IEEE.

Hugo, A., \& Pistikopoulos, E. N. (2005). Environmentally conscious long-range planning and design of supply chain networks. Journal of Cleaner Production, 13(15), 1471-1491.

Hwang, C. L., Masud, A. S. M., Paidy, S. R., \& Yoon, K. P. (1979). Multiple objective decision making, methods and applications: a state-of-the-art survey (Vol. 164). Berlin: Springer.

Ilgin, M. A., \& Gupta, S. M. (2010). Environmentally conscious manufacturing and product recovery (ECMPRO): a review of the state of the art. Journal of Environmental Management, 91(3), 563-591.

Jayaraman, V., Guide Jr, V. D. R., \& Srivastava, R. (1999). A closed-loop logistics model for remanufacturing. Journal of the operational research society, 50(5), 497-508.

Jayaraman, V., Patterson, R. A., \& Rolland, E. (2003). The design of reverse distribution networks: models and solution procedures. European Journal of Operational Research, 150(1), 128-149.

Jiménez, M., Arenas, M., \& Bilbao, A. (2007). Linear programming with fuzzy parameters: an interactive method resolution. European Journal of Operational Research, 177(3), 1599-1609.

Klibi, W., Martel, A., \& Guitouni, A. (2010). The design of robust value-creating supply chain networks: a critical review. European Journal of Operational Research, 203(2), 283-293.

Ko, H. J., \& Evans, G. W. (2007). A genetic algorithm-based heuristic for the dynamic integrated forward/reverse logistics network for 3PLs. Computers \& Operations Research, 34(2), 346-366.

Krikke, H. R., van Harten, A., \& Schuur, P. C. (1999). Business case Oce: reverse logistic network re-design for copiers. OR-Spektrum, 21(3), 381-409.

Lai, Y. J., \& Hwang, C. L. (1992). A new approach to some possibilistic linear programming problems. Fuzzy Sets and Systems, 49(2), 121-133.

Lai, Y. J., \& Hwang, C. L. (1993). Possibilistic linear programming for managinginterest rate risk. Fuzzy Sets and Systems, 54(2), 135-146.

Lee, D. H., \& Dong, M. (2008). A heuristic approach to logistics network design for end-of-lease computer products recovery. Transportation Research Part E: Logistics and Transportation Review, 44(3), 455-474.

Lee, J. E., Gen, M., \& Rhee, K. G. (2009). Network model and optimization of reverse logistics by hybrid genetic algorithm. Computers \& Industrial Engineering, 56(3), 951-964.

Li, X. Q., Zhang, B., \& Li, H. (2006). Computing efficient solutions to fuzzy multiple objective linear programming problems. Fuzzy Sets and Systems, 157(10), 1328-1332.

Linton, J. D., Klassen, R., \& Jayaraman, V. (2007). Sustainable supply chains: an introduction. Journal of Operations Management, 25(6), 1075-1082.

Listeş, O., \& Dekker, R. (2005). A stochastic approach to a case study for product recovery network design. European Journal of Operational Research, 160(1), 268-287.

Lu, Z., \& Bostel, N. (2007). A facility location model for logistics systems including reverse flows: The case of remanufacturing activities. Computers \& Operations Research, 34(2), 299-323.

Meade, L., Sarkis, J., \& Presley, A. (2007). The theory and practice of reverse logistics. International Journal of Logistics Systems and Management, 3(1), 56-84.

Meepetchdee, Y., \& Shah, N. (2007). Logistical network design with robustness and complexity considerations. International Journal of Physical Distribution \& Logistics Management, 37(3), 201-222.

Melo, M. T., Nickel, S., \& Saldanha-da-Gama, F. (2009). Facility location and supply chain management-A review. European Journal of Operational Research, 196(2), 401-412.

Min, H., Ko, C. S., \& Ko, H. J. (2006). The spatial and temporal consolidation of returned products in a closed-loop supply chain network. Computers \& Industrial Engineering, 51(2), 309-320.

Mutha, A., \& Pokharel, S. (2009). Strategic network design for reverse logistics and remanufacturing using new and old product modules. Computers \& Industrial Engineering, 56(1), 334-346.

Negoita, C. V., Zadeh, L. A., \& Zimmermann, H. J. (1978). Fuzzy sets as a basis for a theory of possibility. Fuzzy sets and systems, 1, 3-28. 
Özkır, V., \& Başlıgil, H. (2013). Multi-objective optimization of closed-loop supply chains in uncertain environment. Journal of Cleaner Production, 41, 114-125.

Pati, R. K., Vrat, P., \& Kumar, P. (2008). A goal programming model for paper recycling system. Omega, 36(3), 405417.

Pishvaee, M. S., Farahani, R. Z., \& Dullaert, W. (2010a). A memetic algorithm for bi-objective integrated forward/reverse logistics network design. Computers \& Operations Research, 37(6), 1100-1112.

Pishvaee, M. S., Jolai, F., \& Razmi, J. (2009). A stochastic optimization model for integrated forward/reverse logistics network design. Journal of Manufacturing Systems, 28(4), 107-114.

Pishvaee, M. S., Kianfar, K., \& Karimi, B. (2010b). Reverse logistics network design using simulated annealing. The International Journal of Advanced Manufacturing Technology, 47(1-4), 269-281.

Pishvaee, M. S., Rabbani, M., \& Torabi, S. A. (2011). A robust optimization approach to closed-loop supply chain network design under uncertainty. Applied Mathematical Modelling, 35(2), 637-649.

Pishvaee, M. S., \& Razmi, J. (2012). Environmental supply chain network design using multi-objective fuzzy mathematical programming. Applied Mathematical Modelling, 36(8), 3433-3446.

Pishvaee, M. S., \& Torabi, S. A. (2010). A possibilistic programming approach for closed-loop supply chain network design under uncertainty. Fuzzy sets and systems, 161(20), 2668-2683.

Quariguasi Frota Neto, J., Walther, G., Bloemhof, J., Van Nunen, J. A. E. E., \& Spengler, T. (2009). A methodology for assessing eco-efficiency in logistics networks. European Journal of Operational Research, 193(3), 670-682.

Sakawa, M., Yano, H., \& Yumine, T. (1987). An interactive fuzzy satisficing method for multiobjective linearprogramming problems and its application. Systems, Man and Cybernetics, IEEE Transactions on, 17(4), 654-661.

Salema, M. I. G., Barbosa-Povoa, A. P., \& Novais, A. Q. (2007). An optimization model for the design of a capacitated multi-product reverse logistics network with uncertainty. European Journal of Operational Research, 179(3), 10631077.

Sawik, T. (2011). Supplier selection in make-to-order environment with risks. Mathematical and Computer Modelling, 53(9), 1670-1679.

Selim, H., \& Ozkarahan, I. (2008). A supply chain distribution network design model: an interactive fuzzy goal programming-based solution approach. The International Journal of Advanced Manufacturing Technology, 36(3-4), 401-418.

Shaw, K., Shankar, R., Yadav, S. S., \& Thakur, L. S. (2012). Supplier selection using fuzzy AHP and fuzzy multiobjective linear programming for developing low carbon supply chain. Expert Systems with Applications, 39(9), $8182-8192$.

Shen, Z. (2007). Integrated supply chain design models: a survey and future research directions. Journal of Industrial and Management Optimization, 3(1), 1.

Srivastava, S. K. (2007). Green supply-chain management: a state-of-the-art literature review. International Journal of Management Reviews, 9(1), 53-80.

Torabi, S. A., \& Hassini, E. (2008). An interactive possibilistic programming approach for multiple objective supply chain master planning. Fuzzy Sets and Systems, 159(2), 193-214.

Üster, H., Easwaran, G., Akçali, E., \& Cetinkaya, S. (2007). Benders decomposition with alternative multiple cuts for a multi-product closed-loop supply chain network design model. Naval Research Logistics (NRL), 54(8), 890-907.

Wang, F., Lai, X., \& Shi, N. (2011). A multi-objective optimization for green supply chain network design. Decision Support Systems, 51(2), 262-269.

Wang, H. F., \& Hsu, H. W. (2010a). A closed-loop logistic model with a spanning-tree based genetic algorithm. Computers \& Operations Research, 37(2), 376-389.

Wang, H. F., \& Hsu, H. W. (2010b). Resolution of an uncertain closed-loop logistics model: An application to fuzzy linear programs with risk analysis. Journal of Environmental Management, 91(11), 2148-2162.

Wang, J., \& Shu, Y. F. (2007). A possibilistic decision model for new product supply chain design. European Journal of Operational Research, 177(2), 1044-1061.

Zimmermann, H. J. (1978). Fuzzy programming and linear programming with several objective functions. Fuzzy Sets and Systems, 1(1), 45-55.

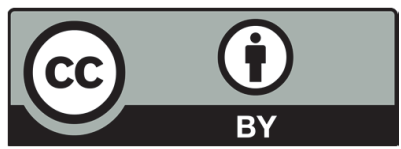

(C) 2016 by the authors; licensee Growing Science, Canada. This is an open access article distributed under the terms and conditions of the Creative Commons Attribution (CCBY) license (http://creativecommons.org/licenses/by/4.0/). 